\title{
El Llibre dels ocells de caça, o Flors de les receptes medicinals per a ocells de caça
}

\section{Book of hunting birds or Florilegium of medicinal recipes for hunting birds}

\author{
Marinela Garcia Sempere \\ marinela@ua.es \\ Universitat d'Alacant
}

Institut Interuniversitari de Filologia Valenciana

\begin{abstract}
Resum: Edició d'un dels textos de falconeria medievals conservats en català, interessant per l'extensió i per la qualitat de la redacció, amb un vocabulari ric, variat i especialitzat. Està format per la unió de dos tractats diferents i apareix recollit en un extens volum miscel lani copiat en el segle XV en el qual es recullen, també, altres tractats, de cosmètica femenina, de cuina, etc. Tot i que les fonts del Llibre dels ocells de caça, o Flors de les receptes medicinals per a ocells de caça semblen molt abundants, anotem ací l'edició amb la que permet un acarament més evident per la proximitat entre el text llatí i el català, ja que n'és la font directa; es tracta del De falconibus de sant Albert el Gran o sant Albert Magne, del qual hi ha una versió parcial entre els folis 122v i 138v del manuscrit.
\end{abstract}

Paraules clau: edició, tractats de falconeria, edat mitjana, sant Albert el Gran

\begin{abstract}
This work focuses in the edition of a medieval falconry text written in Catalan. This is an interesting text because of its length and the quality of its language, with a rich, varied, and specialized vocabulary. It joins two different treatises, copied into a larger 15 th-century miscellaneous manuscript, in which other treatises are also collected, such as one on women's cosmetics, another on cooking, etc. Although the sources of the Llibre dels ocells de caşa, o Flors de les receptes medicinals per a ocells de caça seem very abundant, we annotate the edition with the source allowing a more direct comparison because of the proximity between the Latin and Catalan text; namely, the De falconibus by St. Albert the Great, of which there is a partial version in folios $122 \mathrm{v}$ to $138 \mathrm{v}$ of the manuscript.
\end{abstract}

Key words: text edition, treatise, falconry, Middle Ages, St. Albert the Great

DATA PRESENTACIÓ: 14/04/2021 ACCEPTACIÓ: 30/04/2021 · PUBLICACIÓ: 01/06/2021

1 Aquest treball s'inscriu en el marc del Projecte d'investigació subvencionat per la Generalitat Valenciana «La falconeria a la Corona d’Aragó durant la baixa edat mitjana: edició crítica de textos i estudi de documentació arxivística» (AICO/2019/255). 


\section{Marinela Garcia Sempere. El Llibre dels ocells de caça, o Flors de les receptes medicinals per a ocells de caça}

\section{Introducció}

Aquest treball ofereix l'edició del text de falconeria Llibre dels ocells de caça, o Flors de les receptes medicinals per a ocells de caşa (LOC), conservat en el manuscrit 68 de la Biblioteca Universitària de Barcelona, (f. 108v-150v), i datat en el segle XV. Me'n vaig ocupar fa uns anys (Garcia 2005 i 2005b) per estudiar-ne una de les fonts principals, el De falconibus de sant Albert el Gran, per suggerir la possible aparició d'altres fonts, com ara el De avibus tractatus d'Adelard de Bath o el Tractat per l'art de la caça, ${ }^{2}$ com també per remarcar algunes de les característiques del text i del manuscrit. En aquell moment en vaig transcriure només alguns fragments per complementar el que deia, però ja vaig poder comprovar que l'extensió, la riquesa lingüística, com també el vocabulari d'especialitat que s'hi recullen, justifica amb escreix l'edició completa que ara presente. Des del 1999 he anat publicant tractats catalans de falconeria que encara eren inèdits però no havia tingut oportunitat de publicar el LOC. Aquest monogràfic ha permès que reprenga el treball antic sobre el LOC i que en revise el manuscrit per a l'edició.

El manuscrit 68 és un volum miscel lani en el qual es recullen obres relacionades principalment amb activitats de les corts nobiliàries, com ara la cura de les aus de caça, dels cavalls i dels gossos, com també la cuina o la cosmètica femenina. El manuscrit ha estat descrit per Miquel (1958), Miralles / Toldrà (2000), Santanach (2003), BITECA (manid 1194) i Querol (2018). El LOC hi apareix esmentat en diferents ocasions, com es pot veure més avall, i de maneres diferents, per això, he optat per mantenir el títol que hi ha en l'índex del foli $8 \mathrm{v}$, que és el que va preferir Miquel Rossell, Llibre dels ocells de caça, i que és el nom amb què es coneix tradicionalement el tractat. Però també he afegit l'altre títol Flors de les receptes medicinals per a ocells de caça, que es pot deduir pel que es diu al començament del tractat i que és el que fa servir Querol (2018).

Si el manuscrit és un volum miscel lani, el LOC també és una obra miscel lània, ja que, després d'una introducció, hi ha una primera part o primer tractat que acaba en el foli $138 \mathrm{v}$ de manera brusca i, en el foli següent, comença un segon tractat amb una numeració nova: «Capítol primer. Per falcó costibat de ventrel», etc. Al final d'aquest segon tractat hi ha un capítol únic que parla sobre els gossos. Pel que fa al primer tractat, en un dels meus treballs anteriors (Garcia 2005) el vaig dividir en dos blocs, el segon dels quals correspondria als folis $122 \mathrm{v}-138 \mathrm{v}$, que són els que contenen la traducció parcial de l'obra d'Albert el Gran. ${ }^{3}$ En efecte, aquesta segona part del primer tractat, tradueix parcialment la secció 40 del llibre XXIII, De falconibus, asturibus, accipitribus, del De Animalibus d'Albert el Gran, capítols V-XVI i acaba de manera brusca en el capítol XVII sobre el regiment dels falcons, del qual tradueix només les primeres línies.

2 Hi vaig indicar que la successió dels primers nou capítols del llibre d'Adelard de Bath es reprodueix en aquesta obra. A més, vaig transcriure alguns fragments que coincidien amb el Tractat per l'art de la caça, en el mateix manuscrit en què hi ha també el Tractat de cetreria de Rocabertí.

3 Querol $(2018,1,378)$ considera que la divisió en dos blocs no ha de dependre de la font i situa la divisió en el foli $119 \mathrm{v}$, que correspon al capítol «De les nobleses dels falcons i d'altres ocells de rapinya».

SCRIPTA, Revista internacional de literatura i cultura medieval i moderna, núm. 17 / juny 2021 / pp. 280 - 336 ISSN: 2340-4841·doi:10.7203/SCRIPTA.17.20915 


\title{
Marinela Garcia Sempere. El Llibre dels ocells de caça, o Flors de les receptes medicinals per a ocells de caça
}

Querol (2018) ha estudiat recentment els tractats de falconeria catalans en conjunt, com també ha fet una revisió molt completa de les mostres conservades d'aquest gènere en la tradició romànica i en la no romànica. Pel que fa al LOC, ha detectat nombroses fonts i ha fet una edició comentada en la qual compara cada capítol amb les fonts i les obres del gènere que hi poden tenir relació. També ha inclòs en el text de l'edició títols que no hi eren i ha reconstruït fragments segons la seua lectura de les fonts.

L'edició del text del LOC que presente ací és una edició del text tal com apareix en el manuscrit, anotada amb les variants que presenta la font que es percep més clarament, el De falconibus d'Albert el Gran (AG), ${ }^{4}$ que se segueix amb bastant fidelitat ja que n'és la font directa, i amb les notes textuals i explicatives corresponents. He afegit, també, algunes de les notes explicatives que aporta Querol (JQ) en el seu documentat estudi. Tot i que el text pròpiament dit comença en el full 108v, he recollit els altres fragments del manuscrit en què es fa esment del LOC, com també l'índex. Així, al començament del manuscrit llegim (f. Or) que hi ha recollit un «Tractat dels aucells». Més avant (f. $7 r$ ) es torna a fer referència al LOC:

\begin{abstract}
Así comensan los libres de madesines fetes de diverses reseptes que é tretes del Tresor de Beutat, segons aquelles he trobades pus nobles e pus aprovades per esperiència d'algunes notables persones e, per ço, en los presents libres intitulats Flos de les dites reseptes, los quals parlan primerament de banys e escubes e paladors d'altres cosses per mundificar les inmundícies del cos de les dones e de la balessa de la cara e d'altres pertides del cos; aprés parla de diverses madesines per ocels de cassa, compost de reseptes provades; e de manescalia de bèsties, conpost de reseptes provades fetes per diversos dochtors e altres en açò esperts; e de totes maneres de confits de sucre hi de mel; e encara, de totes maneres de potatges de cuinar.
\end{abstract}

I ja en el f. 8v es presenta el llibre, amb un índex:

[8v] Así comense lo segon libre, dels alcels de cassa, qui trachta de diverses madesines, compost de reseptes provades segons apar per los dits capítols sagüens:

Capítol primer. Per falcó costibat de ventrel, com és conegut ne si 11 vols curar fes la medesina sagüent. En ca. CXXXXIIII. ${ }^{5}$

Capítol segon. Per a pentex de ocel. En ca. CXXXXV.

Capítol terç. A grans [9r] qui ss fan en la boca dels alcels qui s'apelen garniols. En cartes CXXXXVI.

Capítol quart. Aucel qui age lo cap inflat e lo paledar. En ca. CXXXXVII.

Capítol Vè. Per cascadura de ocel. En ca.

Capítol VIè. Si vols tanir sans l'aucel tot l'any, fes so qui ‘s saguex miyant abril, ans que $l$ metes en muda. En ca.

Capítol VIIè. Per $^{6}$ baxar falcó. En cartes.

\footnotetext{
4Per al text de l'obra de sant Albert el Gran he seguit l'edició de Stadler (1916-20). També he fet servir algunes indicacions de l'estudi de Smets (2010), amb qui vaig tenir ocasió de parlar en diferents ocasions d'aquesta obra catalana (ibid. p. 55).
}

5 En ca.] Deu voler dir 'en cartes' perquè apareix així desenvolupat en alguns capítols. És a dir, es refereix al número del foli en què apareix el capítol, i aquest número està afegit, quan hi apareix, amb una tinta diferent, deu ser una altra mà.

6 Per] pe ms.

SCRIPTA, Revista internacional de literatura i cultura medieval i moderna, núm. 17 / juny 2021 / pp. 280 - 336 
Marinela Garcia Sempere. El Llibre dels ocells de caça, o Flors de les receptes medicinals per a ocells de caça

Capítol VIIIè. Per porets. En cartes.

Capítol VIIIIè. A tota trencadura de dit e de mà o de cama de falcó o tot altre ocel. En ca.

Capítol Xè. Per falcó o altre ocel qui no pugua gitar la gorga ne la pugua pessar. En ca.

Capítol XIè. Per passar bé los pasts a falcó o altre ocel. En ca.

Capítol XIIè. Per ocel malalt. En ca.

Capítol XIIİè. Per alcel que om no sap quina malaltia à. En ca.

Capítol XIIIIè. Per alcel qui à fàstich e no pot menjar. En ca.

Capítol XVè. Per aucel qui à pepida, e és malaltia qui dóna tost la mort. En ca.

Capítol XVIè. A dolor de cap de ocel qui comens als uls. En ca.

Capítol XVIIè. Conexensa de l'alcel com à febre. En cartes.

Capítol XVIIIè. A lubrifoli, so és, aucel qui no pot volar axí com à acostumat. En cartes.

Capítol XVIIIIè. Conexensa com l'aucel à mal en la vaxigua.

Capítol XXè. A mal de ulls. En cartes.

Capítol XXIè. Aucel qui git sanch. En ca.

Capítol XXIIè. Aucel qui age pedre. En ca.

Capítol XXIIIè. Altre madesina milor de mal de pedre. En ca. [9v]

Capítol XXIIIIè. Aucel qui age poys. En ca.

Capítol XXVè. Per aucel qui age poys, altre manera. En ca.

Capítol XXVIè. Alcel qui à cuchs e amagresca. En cartes.

Capítol XXVIIè. A conexense de alcel qui à mal d'escuma. En ca.

Capítol XXVIIIè. A tota malaltia que alcel age als uls, especial en la lil la blanqua. En ca.

Capítol XXVIIIIè. Per porets de ocel. En ca.

Capítol XXXè. A pentax de ocel. En ca.

Capítol XXXIè. Aucel qui tengua sanch en la gorga. En ca.

Capítol XXXIIè. A sobròs de ocell. En ca.

Capítol XXXIIIè. A fer mudar tost ocell. En ca.

Capítol XXXIIIIè. Aucel qui no pusque ben pesar la vianda. En ca.

Capítol XXXVè. Aucel qui git la cran. En ca.

Capítol XXXVIè. Aucel qui té plomada o curayl vella en la gorga. En cartes

Capítol XXXVIIè. Aucel qui té cran al matí e no la pot pessar. En ca.

Capítol XXXVIIIè. Per porets de ocel. En ca.

Capítol XXXVIIII è. Per aucel qui no puxa engrexar. En ca.

Capítol XXXX è. Aucel qui à dolor en valessa. En cartes.

Así comensen les medesines dels estors:

Capítol XXXXI è. Astor qui aurà sanch. En ca. CLI.

Capítol XXXXIIè. Astor qui no vulla menjar, En ca.

Capítol XXXXIIIè. Astor qui és malalt. En ca.

Capítol XXXXIIIIè. Conexensa com l'astor à mal en la vaxigua. En ca.

Capítol XXXXVè. Astor qui à febre, la conexensa. En cartes. [10r]

Capítol XXXXVIè. Astor qui no pot mudar. En cartes.

Capítol XXXXVIIè. Astor a qui caen les plomes per tinya. En ca.

Capítol XXXXVIIIè. Astor qui à totes les plomes e no pot volar axí com sol. En

Capítol XXXXVIIIIè. Aucel qui à dolor en lo cap. En cartes.

ca.

Capítol Lè. Porgua a tot ocell. En ca.

Capítol LIè. Alcel qui sia acolorat. ${ }^{7}$ En ca.

Capítol LIIè. Aucel qui à gorniols en la boca. En cartes.

Así comensen les medesines dels espervers.

7 acolorat deu voler dir acalorat.

SCRIPTA, Revista internacional de literatura i cultura medieval i moderna, núm. 17 / juny 2021 / pp. 280 - 336 
Marinela Garcia Sempere. El Llibre dels ocells de caça, o Flors de les receptes medicinals per a ocells de caça

Capítol LIIIè. Esperver enreumesat. En ca. CLIII.

Capítol LIIIIè. Altre manera per esperver enreumesat. En ca. CLIII.

Capítol LVè. Altre menera per esperver enreumasat. En ca.

Capítol LVIè. Aucel qui à gelosia. En ca.

Capítol LVIIè. La conexense dels falcons. En cartes.

Capítol LVIIİ̀. A fer mudar ocel. En ca.

Capítol LVIIIIè. Per tanir ocel sa. En ca.

Capítol LXè. Per desinflar mà de falcó o estrènyer. En ca.

Capítol LXIè. Asperver qui à porets. En ca.

Así comensan les madesines dels cans de casa:

Capítol LXIIè. Per ronya ${ }^{8}$ de cans. En ca. CLV.

El text del LOC comença en el f. 108v. En l'edició seguim les normes de transcripció que hem fet servir en la resta de textos del monogràfic i que corresponen, en general, a les utilitzades en l'editorial Els nostres clàssics.

8 ronyal roya ms.

SCRIPTA, Revista internacional de literatura i cultura medieval i moderna, núm. 17 / juny 2021 / pp. 280 - 336 ISSN: 2340-4841 · doi:10.7203/SCRIPTA.17.20915 


\section{Bibliografia}

BITECA: Bibliografia de Textos Antics Catalans, Valencians $i$ Balears. Compiled by Vicenç Beltran, Gemma Avenoza, Lourdes Soriano, Beatrice Concheff. Disponible en: http:/ / sunsite3.berkeley. edu/PhiloBiblon/BITECA/1897.html [fecha de consulta: 7 d'abril de 2021].

Ferragud, C. / Olmos de León, R. M. / Bataller, V. (2021) «Galiana: història d’un facó». Scripta, 17, pp. 413-481.

Garcia, M. (1999) La versió catalana medieval dels tractats de falconeria Dancus rex $i$ Guillelmus falconarius, Alacant, Servei de Publicacions de la Universitat d'Alacant.

Garcia, M. (2005) «El Llibre dels ocells de caşa: una recopilación de saber cetrero del siglo XV», Los libros de caza , ed. De José Manuel Fradejas Rueda, Tordesillas, Instituto de Estudios Iberoamericanos y Portugal, Seminario de Filología Medieval, Universidad de Valladolid, p. 55-68.

Garcia, M. (2005b) «El Llibre dels ocells de caça. Aproximació a un tractat de falconeria del segle XV», Actes del X Congrés Internacional de l'Associació Hispànica de Literatura Medieval, edició a cura de R. Alemany / J. L. Martos / J. M. Manzanaro, Alacant, Institut Interuniversitari de Filologia Valenciana, "Symposia Philologica", 10, II, p. 777-791.

Miquel, F. (1958) Inventario General de Manuscritos de la Biblioteca Universitaria de Barcelona, I. Madrid: Direcciones Generales de Enseñanza Universitaria y de Archivos y Bibliotecas, Servicio de Publicaciones de la Junta Técnica, 1958-1969. - 4 v., p. 71-77.

Miralles, E. / Toldrà, M. (2000) Repertori de manuscrits catalans (1474-1620), II.1, Barcelona, Biblioteca Pública Episcopal i Biblioteca de la Universitat, Direcció d'Eulàlia Duran. Barcelona, Institut d'Estudis Catalans.

Querol, J. (2018) L'art de la falconeria a la Corona d'Aragó durant la baixa edat mitjana: edició $i$ estudi dels tractats escrits en català, tesi doctoral llegida el 14 de novembre de 2018 . http://hdl.handle. net/10803/666811.

Santanach, J. (ed.) (2003) Llibre de totes maneres de confits, Barcelona, Barcino, editat conjuntament amb el Llibre de sent soví, a càrrec de Rudolf Grewe.

Smets, A. (2010) Des faucons. Édition et édude des quatre traductions en moyen français du 'De falconibus' d'Albert le Grand, Lormaye, Jacques Laget, Librairie des Arts et Métiers-Editions.

Stadler, H. (ed.) (1916) Albertus Magnus De Animalibus Libri XXVI nach der Cölner Urschrift. Erster Band. Buch I-XII enthaltend. (Beiträge zur Geschichte der Philosophie des Mittelalters XV). Münster i. W. : Aschendorffschen Verlagsbuchhandlung. XXVI, p. 1-892.

Stadler, H. (ed.) (1920) Albertus Magnus De Animalibus Libri XXVI nach der Cölner Urschrift, zweiter band, buch XIII-XXVI enthaltend. (Beiträge zur Geschichte der Philosophie des Mittelalters XVI). Münster i. W. : Aschendorffschen Verlagsbuchhandlung, XXI, p. 893-1664. 
Marinela Garcia Sempere. El Llibre dels ocells de caça, o Flors de les receptes medicinals per a ocells de caça

\section{Edició del Llibre dels ocells de caça o Flors de les reseptes medicinals per a ocells de caça}

\subsection{Normes d'edició}

a) Seguim com a norma general els criteris d'edició de la col lecció «Els Nostres Clàssics» de l'editorial Barcino.

b) Regularitzem l'ús de les grafies u/v, i/j, c/ç. Reproduïm com a c totes les ç amb valor alveolar, i com a ç totes les c que apareixen davant de les vocals a, o i u, en la majoria de casos per falta del traç corresponent.

c) No marquem el desenvolupament de les abreviatures.

d) Hem reduit sempre les grafies dobles, tant les etimològiques com les no etimològiques si responen només a un únic fonema.

e) Regularitzem la grafia de la nasal palatal nny, yn o nyn $>$ ny.

f) L'accentuació adoptada correspon al timbre vocàlic propi de la variant oriental, zona d'on segurament prové el manuscrit. Usem l'accent diacrític en els casos que indica la normativa actual i, excepcionalment, en altres mots que poden prestar-se a confusió com: àls (altre), là, llà (allà), sí (aixî), à, é i ém (haver), té (tenir), péra/péres (pedra/pedres), mès (participi de metre), etc.

g) Seguim els criteris actuals pel que fa a puntuació, separació de paraules, majúscules i minúscules, apòstrof, guionet, accent i dièresi.

h) Emprem la dièresi damunt la y en mots com aÿna, constituÿdes. En prescindim en els casos de paraules amb h antihiàtica com trihumfo, jahia, traduhit, etc., també les formes verbals de l'imperfet d'indicatiu com deÿa, feïa, hoÿa etc.

i) Representem amb un punt volat la pèrdua d'una vocal en una aglutinació quan no s'hi pot utilitzar l'apòstrof: que 's, vostr apetit, etc.

j) Pel que fa a la numeració de les pàgines, apareix entre claudàtors la xifra de la pàgina acompanyada de $\mathrm{r}$ (recto) o v (verso).

k) Transcrivim com a un/una, dos/dues, tres/terça les xifres romanes i, ia, ii, iia, iii, iiia.

1) Recollim en les notes a peu de pàgina les particularitats següents que presenta el manuscrit:

- Indiquem els casos de mots que cal ometre (e de] de), mots ratllats (per] de per) i mots interlineats (mare \{sua\}] mare sua). També corregim errors (reastràs] restaràs).

- Incloem també en les notes algunes recomanacions per a determinades lectures (belles] Llegiu 'balles'). 


\section{Marinela Garcia Sempere. El Llibre dels ocells de caça, o Flors de les receptes medicinals per a ocells de caça}

\subsection{Edició}

\section{[Llibre dels ocells de caça o Flors de les reseptes medicinals per a ocells de caça] ${ }^{9}$}

[108v] Pus avem perlat dels cavals e de les mules, nesessari és que perlem dels aucells de cassa. E de aquells yo us fassa algun servisi del present libre, lo qual vos he conpost de diverses reseptes que són medesinals per aucells de cassa, segons aquelles é trobades pus nobles e pus aprovades per esperiènsia de algunes notables persones. E per so, en lo present libre, intitulat Flors de les dites reseptes, lo qual libre, senyors de gentils òmens ho de qualsevuylla estament, no us he presomit fer creer que aquel ayats al present nesesari per esmenar vostres gentilesses e en aquelles prou saber, com d'aquelles vos aya Déu prou bestantment dodats entre los altros gentils òmens qui de semblants gràcies se poden alegrar; mas aquest vos he fet e compost per tal que, per alguns accidents qui s'esdevenen en los dits aucells, desminuins les dites gràcies, vos poguéssets de aquells ${ }^{10}$ sevir e hajudar. ${ }^{11}$

[109r] De vostres gentilesses soplicants las vostres benignitats, senyors, que prengau ${ }^{12}$ mon servisi en grat, no segons que la sua valor marex,${ }^{13}$ mas segons la bona afecció e volentat ab què lo dit servisi vos és per mi fet. E per tant com en lo dit Tresor d'on és la present composició treta, dels ocels és feta mensió de diverses madasines, compost de reseptes provades e d'altres cosses per mundificar ${ }^{14}$ e sanar e gorir los alcels, e $\operatorname{los}^{15}$ nodriments de aquels, e coneguen $\mathrm{e}^{16}$ sàpien les natures d'éls, e que sàpien conèxer lo comensament de les malalties dels dits ocels; e vosaltros, yo crech que ya ayats e sapiats ya la manera de les medesines qui són medesinals per algunes cosses que són nesesàries de saber e ésser fet als dits alcels, segons que trobarets per les reseptes presents.

E, primerament, trectarem dels espervers.

9 Sobre el títol de l'obra vegeu Garcia (2005 i 2005b), Santanach (2003) i Querol (2018, 373-374). Per a la transcripció del text he comptat amb l'ajuda d'Antoni Mas, que ha revisat el text $\mathrm{i}$ ha fet algunes esmenes.

10 aquells] aquell $\mathrm{ms}$.

11 bajudar hajudar ms.

12 prengau es pot llegir prengueu, hi ha una correcció en el mot que no s’entén bé.

13 Podria llegir-se també marey perquè la grafia de la x i la de la y són molt semblants en el manuscrit.

14 mundificar, 'netejar, purificar'.

15 los] lo ms.

16 e] the ms.

SCRIPTA, Revista internacional de literatura i cultura medieval i moderna, núm. 17 / juny 2021 / pp. 280 - 336 ISSN: 2340-4841 · doi:10.7203/SCRIPTA.17.20915 


\section{Marinela Garcia Sempere. El Llibre dels ocells de caça, o Flors de les receptes medicinals per a ocells de caça}

Covinent cosa [és] que 1 s nodriments ${ }^{17}$ dels espervers coneguen e sàpien les natures dels aucels. E que sàpien conèxer lo comensament de les malalties dels aucels per $^{18}$ so que $^{19}$ mils pot hom al comensament donar consell que no fa com la malaltia és encarnada. Encara cové que ls nodridors ${ }^{20}$ dels aucels sien hòmens tenprats, sostinents, e no sien jutyadors $[109 \mathrm{v}]$ ne enbriachs ne necligens. Encara cové que sien hòmens que 's sàpien donar grat, que no fassen volar descovinent hora. Encara que no sien hòmens sutzes he lo alè no li puda ne vaya volentés a les putanes. Si asò era, l'esperver no és fet panyós ${ }^{21}$ e temorós.

Deu encara procurar covinentesa de loch e de cel la on lo deu hom nodrir, com no és neguna cosa que tant ajut a llur natura com és soptil he nèdeu, he enasi ${ }^{22}$ soptil él deu ésser nodrit. Deu-se hom encara guardar que hom no meta l'esperver en casa hon haya sotzura ne pudor. $\mathrm{Ne}$, en $1 \mathrm{l}^{23}$ mes de hoctumne que om verema, no pos l'esperver en loch on l'ardor ne la pudor del boliment del vi no 1 puxa tocar, com yo n'é vist per semblant cossa morir. Encara diu hom que, si alguna fembra té les faldes levades he mostre a l'esperver la sua natura, tantost mor. E yo é 'n demanades algunes fembres, que m'an dit que ver és.

Deu ésser l'esperver past axí com de polets pochs denant tots los altres de passarells; ho de cor de moltó. Deu-lo hom, enperò, gardar de carn de moltó, que no ls ne don hom dementre que són malalts. Emperò, si li'n dona hom, trasque'n los nirvis. Guardaràs [110r] que en sanitat ne en destremprament ${ }^{24}$ no li dona hom carn de bou ne de vaca ne de porc. E, si dar-li-n'as, dona-li'n de mascle que sia de un any; mas no li donasses nengun temps carn de truya, com sempre lo auciuria, que carn de vadella li valria més.

Devets saber que ls espervers deuen ésser nodrits delicadament, e mayorment al comensament, que li donaràs les crans ${ }^{25}$ capolades ${ }^{26}$ he dona-li sovín a menjar com, si no u fas al comensament, per ventura defeliria a les plomes qui corrompen e destrohexen. E comensa que hom li fasa paella

17 nodriments] nodridors JQ.

18 per] prer ms.

19 que] quom ms.

20 nodridors] nodrimts $\mathrm{ms}$.

21 panyós, 'que té pany o tel'.

22 enasí, 'enaixí'.

23 lo corregit sobre un altre terme.

24 destrempament, 'indisposició'.

25 crans, llegiu carns. En diferents ocasions el manuscrit dóna cran o crans i sempre es llig en el mateix xentit.

26 capolar, 'tallar a trossets petits'.

SCRIPTA, Revista internacional de literatura i cultura medieval i moderna, núm. 17 / juny 2021 / pp. 280 - 336 


\section{Marinela Garcia Sempere. El Llibre dels ocells de caça, o Flors de les receptes medicinals per a ocells de caça}

faytisca ${ }^{27}$ en què hom li cogua los hous, com són destremprats covinentment los nodrex hom per so com són assats sans. E aperella hom los hous enaxí que sien cuyts en la dita paella ${ }^{28}$ en let ho en aygua. Si, per vantura, en aquesta manera l'esperver no ls volia, mesclaràs ab los hous ensemps un poc de sanch per guissa que vermelleg un poch.

Bona cossa és als espervers novels, com hom los met en muda, que sien alleuyats ${ }^{29}$ en cassa, on puxen estar con se volen a la onbra -he encara als falcons e als astors-, he [110v] quant se volen al sol, com lo sol val a confortar les coses naturals e nodrex les plomes qui crexen. E sovén li deu hom possar aygua en què 's banyen. E deu-se hom gardar que no 1 git de la muda entrò sia ben curat $\mathrm{e}$ bé $^{30}$ axut. E sàpies que, estant en la perxa, més són curats e adelitats, enperò milor cosa és que en la cura feta segons que dit és, sia mudat en la muda, e nn val més.

E manifest és que perfetament és mudat com totes les penes de la coha són egualades; hon, con aquest senyal veuràs, encara fa estar aquell per vIII jorns en la muda, per alò que les penes sien pus fermes e pus dures.

E, quant aquel trauràs de la muda, per so que les penes sien pus fermes, fer-li-as gits ${ }^{31}$ que no sien trop curts ne trop larchs. E no sien fets de cuyr dur perquè no li puxen mal fer. Puys, posa-li la longua ${ }^{32}$ axí com te sia semblant. E, com aquell volràs fer venir a lloura envers tèrcia, garde't que envers lo vespre no li ages feta massa gran gorga. E, com aquell covinentment auràs fermat e los gits li auràs messos, tindràs aquel sovén molt e moltes vegades [al puny $]^{33}$ tro gran nit. E, puys, possar-l'as en la perxa, no massa breu fermat, [111r] domdant e assuauyant tro que bé hi sia acustumat d'estar. $\mathrm{E}$, com lo tindràs en la mà, mena suaument la mà dreta denant ell, adés adés de la una part, adés de l'altra. E, ab una vergua, les ales li tocaràs e la coha, e covinentment les li adoberàs.

E són alguns qui no l'afayten a venir a la mà tro que sien ben domdats ${ }^{34}$ en alguna presó per so que no li puxa seguir algun greuge a l'ocell o alguna mala costuma. Mas, finalment, pus que l'auràs afaytat, que 1 feràs volar; pus que auràs feta alcuna presó d'aucell, si 1 comensa de plomar, lexe'l plomar a la sua volentat, e acostant a l'esperver poc ha poch, e toqua'l e prin-lo mastrívolment e ginyosa, ciulant ab lo tifel ho ab la boca com a fer fa per tal que no se'n fassa farèstech. E, despuys

\footnotetext{
27 faytisca, 'fet a posta'.
}

28 paella] poella $\mathrm{ms}$. amb la $o$ interliniada.

29 alleuyats] o alleuxats.

30 bé interliniat.

31 git, 'corretja que els caçadors fermaven a les cames de les aus de presa'.

32 longa, 'corretja amb què es fermaven els ocells de caça'.

33 al puny] om. ms. seguim JQ.

34 segons JQ hi mancaria un fragment: I l'esparver sigui ben dombdat abans que afaitat. I no tinguis pressa en afaitar l'sparver. 
que aurà past a sa voluntat, segurament lo poràs tocar, emperò deu hom gardar que aquel dia no 1 lex hom volar.

\section{Capítol primer. Qui parla de l'esperver enreumasat ${ }^{35}$}

Com l'esperver és enraumasat e encadernat, ${ }^{36}$ bo és que hom li don carn de ca fresca si fer-se pot, si no, carn de moltó fresca e sadola-[111v]ment dels renyons, enaxí que en dos ho en tres trosos pos hom sengles grans de pebre.

E val encara més a la dita ${ }^{37}$ malaltia si l'enbolques entre dos trossos de pa fresch en aquesta manera: tu auràs alcun drap de li primerament possat per tot lo cors e puys lo pa. Encara més, val que mulles un drap de li en vi tèbeu e que $l$ ne enbolchs. E, com lo auràs axí enbolcat e escalfat, fe tres píndoles en manera de una grosa fava de pebre e de sal e de mantegua. E prin-ne la un e possa-la-li en lo sobirà paladar, e puys fe-li tenir la boca closa, enaxí en guisa que puxa covinentment respirar, e que no puxa la píndola anglotir ne la puxa gitar. Puys posa e met una ploma a le un anaril, e covinentment gita-li'n la reuma. E la dita cossa matexa fe puys a la altre anaril. E puys feu ${ }^{38}$ repossar un poc. E, enaprés, dona-li algun past confortívol. E fes assò entrò sus que sia sa.

Encara li pot hom fer altra medesina bona, ${ }^{39}$ jatsia que om no ss peneda que 1 bany ho hunt l'esperver en la fenta de l'infant mascle qui mam ho sia aletat; e, si menyava de la femna de l'infant encamarada en alguna carn, valria-li ${ }^{40}$ molt. [112r]

Encara catariç $c^{41} \mathrm{al}^{42}$ picat e destrempat ab vi per les narils aquel li mit. E lexar-l'as estar per tot un dia en loch escur. Encara hi val carn de porc nerviós, axí com loc prop lo brahó, dona-li'n un poch; puys, poràs-lo péxer de carn tendre. Encara hi val: mit-li such de ruda ${ }^{43}$ per les narils, e per tot aquel dia no li dons res a menyar.

35 reuma, 'fluxió d'humor en alguna part del cos'.

36 encadernat, 'refredat'.

37 dita] dita $\mathrm{ms}$.

$38 \mathrm{feu}$ ] o potser $f e-u$.

39 bona] altra bona ms.

40 valria-li] volriali $\mathrm{ms}$.

41 catariç terme de difícil lectura. JQ proposa catarn.

42 al all segons JQ.

43 ruda, 'planta rutàcia de l'espècie Ruta graveolens'. 


\section{Marinela Garcia Sempere. El Llibre dels ocells de caça, o Flors de les receptes medicinals per a ocells de caça}

\section{Capítol segon. Qui parla de duranyons ho infladures en la boca}

Duranyons ho infladures, alscunes són senyals que són sechs, alscuns madurs. Si lo esperver à infladures seques, prin una gran pell e enbolca-lo-y; puys, suaument, obri-li la boca, e la infladura seca li rau; ho, si és de fora, tranca-la-li. E, asò fet, aquesta cossa li posa: pebre bé picat, vesch d'arbre, sal he mantega. He d'esò sia fet engüent, he sian-li'n untat aquel loch. E, si la infladura hés homida, prin aygua e mel he vi per agual, sengles pochs, he sia mesclat. Aprés, prin una teula ben calda he calfa-ho tot sobre la teula. E, de la mel que y regualerà per la teula calenta, per la [112v] boca li gitaràs, destil lant e degotant. E, asò fet, tanca-lii la boca, e mit-li una ploma per la naril, enaxí que li’n gits la malaltia ensemps ab aquella licor. $\mathrm{E}$ fe ${ }^{45}$ asò de tres en tres dies fins que sia guarit.

Si l'asperver à closes les anarils, mit-li lo cap en aygua tèbeha, puys feu tirar en carn on aya nirvis, he axí guarrà. Aquesta és la general manera del cap que ${ }^{46}$ sobre les narils, là hon les venes se ajusten, e ajusta-li bé la un ${ }^{47} \mathrm{ab}$ lo altra, axí que no 's pusca fer mal. E, quant asò serà fet, cascuna nuyt, sots una caldera, sol un poc calfada quax tèbeha, lo mit. Emperò, posa sots la caldera pedres hon estiga, per so que no toch en terra, he guarà.

Ítem, a porguar lo cap val que li frec om lo peledar ab sàlvia e que li’n faces tirar ab la carn.

Encara a porguar lo cap val que prengues pegunta en canditat de una fava, e calfa-la axí que 's puxa ${ }^{48}$ tenir al peladar. E prin alcuns grans de stafisiagre he de pebre, enaxí que sien los dits grans un poch trencats, en guisa que 's tenguen a la pagunta. E, de tot asò fes en gissa que li comprenga los enarils. E, puys, fes estar l'esperver a la [113r] raya del sol, fes ${ }^{49}$ que de aquella fluhitat ${ }^{50}$ sia purgat. Enaprés, de past covinent poràs péxer d'aquí anant tot esperver.

\section{Capítol III. Per esperver que git la carn per la boca}

Asperver que git la carn per la boca, don-li hom per lo matí a boura aygua. Puys, fes-lo dejunar e no li dons res a menyar tro al vespre. E, lavors, pex-lo de passarels o pàssares ${ }^{51}$ ho de perdius poques ho d'altros ocells.

44 tanca-li] tanca-ta-li ms.

$45 f e]$ a fe ffet ms.

46 JQ afig: segueix: cou-lo

47 JO afig: peu.

48 puxa] es pot llegir també puya.

49 fes] fins JQ.

50 flubitat, 'superfluïtat'.

51 pàssera, 'ocell de la família dels túrdids, espècie Monticola cyaneus, de color blavós o negrenc per damunt i rossenc per sota, que habita a llocs alts de roques, campanars i edificis ruïnosos, i s'alimenta d'insectes, especialment d'abelles' 


\section{Marinela Garcia Sempere. El Llibre dels ocells de caça, o Flors de les receptes medicinals per a ocells de caça}

\section{Capítol IIII. Altra manera per esperver que git la carn}

Asperver que git la carn per la boca, val que la carn de què 1 deuràs péxer metes en aygua bulent quax enpessant, e que 1 ne pesqua hom. Encara val en assò que hom mull ho unta la carn en such de trifoli. ${ }^{52}$ Mas, emperò, so diu lo mestre de aquesta art, que en Alamaya hohí dir a son frare un provament que no fall, e avia'l provat contra gitament de carn: que prenga hom d'una molsa qui ss fa en la cresta de una co-[113v]so antigua ho de aquella qui és en algunes pedres on ha pessada e passa aygua d'algun riu. E prin aquella e trenca-la ben manut; e, puys, que la reprema règeament e fort. $\mathrm{E}$, asò fet, meta hom aquel such colat en un vaxell nèdeu; e, puys, fa hom estar la carn de què hom deu péxer l'esperver per una nit en aquel such tèbeu. Encara li dix son frare que, si arrancava hom la cuxa a la gualina, axí calda la n'untava hom d'aquel such, que val aytant com si estava tota la nit.

\section{Capítol V. Si l'esperver à pantex}

Así direm de la malaltia dels pits, e direm primerament del polsar. E contra asò val que per lo matí li dons limadura d'aram he pólvora d'orpiment ${ }^{53}$ en cor de colom ho de polla. E dic determenadament que, si d'alguna malaltia te dessesperes de l'esperver, que li dons let de tartuga.

E guarda que, si l'esperver és gras ni ha poys, no li nou. E si l'esperver és magre e ha poys, unta-li de such d'ezxens les plomes, e fe'l estar al sol. Encara fes-li perxe d'un arbre que hom apella sahuc, e sie'n pertida l'ascorxa he estiga en aquella, he guarrà dels pols.

Encara més, a alciure poys val que prengua [114r] om grex de gualines he mesclat ab argentviu. E, puys, unte'n hom un fil de lana, he liga-lo-y hom en lo coll hi en les ales, e unta-lo hom covinentment d'asò prop lo bech, e morran.

Encara més, a alciura poys val: prin femna de cabres e fe'n pólvora ab such de mandrastre ${ }^{54}$ destremprat, e la ${ }^{55}$ carn frescha de què 1 deus péxer li’n mulla en asò, he garrà. Alguns unten la carn que deu menyar en grex d'oques e de gualines per auciure los poys.

Encara més, val per alciure poys destemprament d'orpiment picat ab aygua, he unta-li primerament les promes ${ }^{56}$ totes. Enaxí ho feÿa mestre Joan Alamany a Bolunya a son esperver. E lo mestre aquest demané-li si l'orpriment destrouia les penes, e respòs-li que no. Encara los de ultramar fan assò als falcons e als espervers, e con bé són axí untats, semblen ${ }^{57}$ de color groga per rahó de l'horpiment.

52 trifoli, 'trèvol'.

53 orpiment, 'trisulfur d'arsènic, de color groc de llimona, molt tòxic'.

54 mandrastre, 'mendastre, menta borda'.

55 e la] Repetit ms.

56 promes] llegiu 'plomes'.

57 semblen] semble ms.

SCRIPTA, Revista internacional de literatura i cultura medieval i moderna, núm. 17 / juny 2021 / pp. 280 - 336 ISSN: 2340-4841 · doi:10.7203/SCRIPTA.17.20915 


\section{Marinela Garcia Sempere. El Llibre dels ocells de caça, o Flors de les receptes medicinals per a ocells de caça}

Encara més, val per matar poys: prin pebre e orpiment he pica-ho bé. Puys d'asò, tu lo salpica entre les plomes, que sien ruxades ab aygua, ho ab aygua-ros, que dien que més val. E, puys, en una tovallola blanca, enbolique'l, e tin-lo axí una estona e veurets tots los poys en la tovallola, axí que s'hixen d'ell per sa gran cuxor he forsor de la madacina.

\section{Capítol vi. Si l'esperver à tinyes, e alguns ho apellen formiga [114v]}

Si l'esperver à tinyes — ho per alguns és apellat formiga_-, unta'l ab mel, puys gite-y pólvora de adramén, ${ }^{58}$ escorxa ${ }^{59}$ de frexe ${ }^{60}$ e pólvora d'exens e desa'l bé bullit en vinagre, e unta-li lo loch de les tinyes, e da-li de la roge ${ }^{61}$ e de la peradella. ${ }^{62}$

Ítem, si les penes rohen tinyes, val carn d'ase cuyta en sanch de hom. E, axí matex, val carn de boch messa en vinagre, e que li'n do hom. E unta-li hom la carn e 1 past ${ }^{63}$ ab such d'una erba a qui diu hom barba jovis ${ }^{64}$. Encara val per tinyas: unta-li tot lo cors de such de castar ${ }^{65}$ un poch tèbeu, e, en aquell matex such, lo past de l'aucel unta. Encara se fa molt nobla ungüent qui és bo en asò del such del fanoll e de sofre e d'ergentviu contre les tinyes.

\section{Capítol vir. Qui parla con l'asperver à una malaltia qui s'apella falera}

Alguns dien que falera no s pot curar, e aquels qui ho dien no saben fer depertiment entre roptura e trancament. E falera com ruptura no és curable. Felera, emperò, segons aquest mestre, se pot curar. He és dita falera del faell, com la còlera ${ }^{66}$ roga lavors abunda e per tot lo cors és escampada, en tant que 1 bech e les cames e los peus desco-[115r]loren. E és senyal d'asò que l'esperver és pus forihós e pus hirat que no sol.

A la qual malaltia fa hom aytal cura: prin una erba qui nex en alguns pochs rius, la qual alguns apellen helechtrom, los altres, botich, ${ }^{67}$ e los englesos la apellen en lur lengatge 'negre erba'. E fa

58 adrament, 'tinta'.

59 escorxa] <i natró > e scorxa JQ.

60 frexe] frege <e moriran. E> JQ.

61 de la roge] <pólvora de l'arrel de la roge> JQ. Roge, roja, 'planta rubiàcia del gènere Rubia'.

62 paradella, 'herba de la família de les poligonàcies de diferents espècies del gènere Rumex'.

63 hom la carn e lpast el past JQ.

64 barbajovis, 'planta lleguminosa'.

65 castar] cascall JQ.

66 còlera] cobera ms. còlera JQ.

67 botic] boric JQ.

SCRIPTA, Revista internacional de literatura i cultura medieval i moderna, núm. 17 / juny 2021 / pp. 280 - 336 ISSN: 2340-4841 · doi:10.7203/SCRIPTA.17.20915 


\section{Marinela Garcia Sempere. El Llibre dels ocells de caça, o Flors de les receptes medicinals per a ocells de caça}

lo ram quadrat ${ }^{68}$ e les fulles són semblans a grans ${ }^{69}$ d'ortigues, e fan-se al cap de la erba uns grans quax a raÿms. Hon, anans que hom li'n do a menyar a l'esperver qui ha aquesta malaltia, unta la carn ab lo such de la dita erba e da-li'n.

\section{Capítol viII. Qui parla com l'asperver à febra ni com és conegut}

Lo esperver és conegut que à febra com tanca los ulls sobre la perxa ne dorm, e fa lo cap inflat. E falos hom aytall cura: que 1 banya hom en caldo on aya cuyta grua.

Ítem, trau such ${ }^{70}$ de una erba qui s'epella grumell, ${ }^{71}$ he unta-li la carn que li deràs. Ítem, de la sament de la dita erba faràs pólvora, la qual mescla ab la carn que li deràs. Ítem, unta la carn ab such de juyuert, he guarà.

Conés constibat, so és, que no potesmirlar, $[115 \mathrm{v}]$ da-liab lo past fel de guall ho caragols blanchs a menyar. Ítem, com esmirla massa sovén, axí com aquells qui an desentiri, cou hom la malva major ${ }^{72}$ ab grex de porch fresch, ${ }^{73}$ e d'asò un poc ab una cullera ${ }^{74}$ per la boca li gita tebet.

Ítem, en asò prin aytant com la quarta part de una amella ${ }^{75}$ de escamoneya e de comí atretant, e pica-ho ab tant de porch gras, he dona-li’n, e guarrà. E, si per aventura no pot asò retanir, mescla-ho bé ab clara d'ou e mit-lo-y per la boca.

Encara contra esmirlar, prin les fulles de una erba qui à nom jusquiami, e da-li a beura del such.

Encara, per aquests senyals conexeràs la febra als aucells: primerament, que li pengen les ales e té lo cap bax en eli, ${ }^{76}$ e pren lo past ab fàstig, ho a vagades golossament; e que s'esdevie ${ }^{77}$ en si matex malament; a veguades tremola, donchs, así demostra. ${ }^{78}$

68 quadrat quadrat <com a rama> JQ.

69 grans] gras $\mathrm{ms}$.

70 tran such] <si té pedre, > trau such JQ.

71 grumell, 'nom de certa herba'.

72 malva major] malva $<i$ la $>$ la saturiga JQ.

73 fresch] fresch $<i$ amb aigua $>$ JQ.

74 ab una cullera] <quan sigui cuit de manera òptima,> ab una cullera JQ.

75 amella] malla JQ.

76 en eli, 'a punt de desmaiar-se o de morir'.

77 se sdevie] se n'esvie JQ.

78 demostra] demostra $<$ semblant de fret $>$ JQ.

SCRIPTA, Revista internacional de literatura i cultura medieval i moderna, núm. 17 / juny 2021 / pp. 280 - 336 


\section{Marinela Garcia Sempere. El Llibre dels ocells de caça, o Flors de les receptes medicinals per a ocells de caça}

Cura contra la febra: que li deràs carn de galina untada ab such de artimísia dues vaguades ho tres. Encara val a la febra que lichs la un peu de l'esperver bé estret, e parrax una vena, he sagna'l en aquella dues vagades covinentment.

Ítem, prin alò qui és entre l'escorxe d'un arbre, qui à nom gunyiperi, ${ }^{79} \mathrm{e}$ puys fe'n pólvora e da-li’n a x vegades, enaxí que li'n dons la un dia e no l'altre.[116r]

\section{Capítol viIII. Per alsel qui a puhagre ${ }^{80}$}

A curar puhagra, prin escorxa de frexa e de pomer e de naronya ${ }^{81}$ Puys, couràs aquests tant en aygua fins que sia espès, axí com a tinta, e lexe-ho refredar. Pux, enadex-i un poc de sagí ${ }^{82}$ vell. E, asò fet, prin l'esperver e unta-li les mans e les cames, ell estant en una losa, molt que sia untat de asò damunt dit.

Ítem més, una altra cura que aguí de un fill de cavaller qui axí curava en cassa del rey: que prenia les nous verdes e trehe'n lo such he mesclave'l ab altra tant de vinagra, e d'aquel untava-li les mans. E, si à porets, emperò, que 'n sien trets. E, si era que tots los peus agués inflats, asò los li estreny.

\section{Capítol x.. Com l'asperver à fàstich e sequetat}

Si l'esperver à fàstich e sequetat, pren hom un hou debatut he cou-lo en una pella ${ }^{83}$ nèdeha ab let de cabres. E, com lo couràs, guarda'l de fum; puys, dóna-li a menyar. E, si bé lo fa esmirlar, de mantinent d'asò serà deliure sens dupta. [116v]

\section{Capítol XI. Si l'esperver à tinya que li destrouexen les penes}

Si l'esperver à tinya, so és, que li destrouexen les penes, mit una gota de bàlsem en lo forat de la pena. E sàpies que per asò les tinyes són destrouides e mortes, $\mathrm{e}$ ' $\mathrm{n}$ aquel loch novelles penes exiran. E, si lo forat on deu axir la pena és tencat, hobre hom aquell covinentment ab un grafi ${ }^{84} \mathrm{~d}$ 'argent

\footnotetext{
79 genebre, 'arbust de la família de les cupressàcies, espècie Juniperus communis, molt ramós, de fulles linears punxants i més llargues que el fruit, que és axil lar, globós, de color blau fosc i cobert d’una pols blanquinosa'.

80 poagre, 'gota dels peus'.

81 de naronya] $<$ de roure novell $i$ de $>$ garanyoner $\mathrm{JQ}$.

82 sagi] sabó JQ.

83 pella] deu ser paella.

84 grafi, 'punxó'.
}

SCRIPTA, Revista internacional de literatura i cultura medieval i moderna, núm. 17 / juny 2021 / pp. 280 - 336 ISSN: 2340-4841 · doi:10.7203/SCRIPTA.17.20915 


\section{Marinela Garcia Sempere. El Llibre dels ocells de caça, o Flors de les receptes medicinals per a ocells de caça}

que sia calent. Puys, pren hom una osqueta de fus ${ }^{85}$ ho una cossa largueta semblant a fus ho de gra de forment, axí que puxa entrar per aquel foradell, e tengua-ho entre aquella pena con deya créxer. Emperò, si hi met hom per lo cudell ${ }^{86}$ per on deu axir la ploma una caleta ${ }^{87}$ de mel cuyta a la forma damunt dita, hi val més.

\section{Capítol xII. Qui parla que si s'esperver pert alguna ungla}

Si l'esperver pert alguna ungla, ab un coltellet, qui aya la punta corba, soptilment en la fi del peu, là d'on aurà perduda, li trencaràs un poch, quax raent; he crexerà-y altre ungla. E y pots fer altra cossa millor, que prengua hom [117r] una candela encessa, he ab un poc de cotó que crem hom lo loch d'on la ungla és cahuda. E, puys, que lo y unta hom ab mel, e lich-lo-y hom ab un poch de cotó. E lex l'om estar axí per viII dies.

\section{Capítol XIII. Qui parla com l'esperver és malalt e tèssich}

Com l'asperver és malalt he tèsich, dona-li coloma salvatge a menyar e, si bé cou haquest past, viurà. Deus, emperò, saber que atart ${ }^{88}$ esperver és tèsich e no li esdevé sinó per longuesa de bech com l'anguolir de la carn qui s'acosta al bech; he, tant treballa, que [ix-li] ${ }^{89}$ escuma per los narils; hon, per aytal agreuyament, lo seu leu se nafra. E axí, poc a poch, per lo naframent del leu encorra una malatia que hom apella tíssich. Donchs, con veuràs que aurà lo bec massa larch, covinenment aminvaràs-lo-li. E fes-lo péxer en hos hon aya nirvis, per so que 1 bech se puxa mils aminvar e afaytar. E, si per aventura, per necligència és tornat tíssich, [116v] fer-li as ${ }^{90}$ aytal cura: prin dues parts de grex de porch e fon-lo; en asò, mescle-y la tersa part de ruda e de malva he d'api. E mescla-ho bé e da-li d'asò a l'esperver ${ }^{91}$ prop del foch. E asò fes aprés lo past de la carn.

85 fus, 'barreta de fusta rodona, lleugerament cònica, que pel cap més prim té una incisió (l'osca) i pel cap gruixut acaba amb un disc, i serveix, quan es fila a mà, per a tòrcer el fil i enrotllar-lo així com es va formant'.

86 cudell, 'forma que apareix en Flos medic. fols 23 vo i 121 vo, i que probablement és una error de còpia per tudell. Es tracta de la base de la ploma, el canó, tal com expliquen Ferragud i Olmos en el treball que es recull en aquest mateix monogràfic «Galiana: història d'un falcó»: D’altra banda, quan el trencament havia tingut lloc més cap a la base de la ploma, la fixació de la nova ploma es feia introduint la pròpia base d'aquesta, el canó, que s'anomenava tudell, per l'interior del fragment que romania en l'ala o la cua de l'au. A aquesta tècnica de reparació de la ploma es referien els caçadors amb l'expressió «escatir de tudell».Però els significats de tudell no concorden molt amb el que s'hi diu: 'canonet metàl lic corbat que es fixa a la part lateral superior del tub de certs instruments de buf, i en l'extrem lliure del qual s'ajusta l'embocadura' (Ferragud \& Olmos \& Bataller 2021: 444).

87 caleta, 'manyoc de desfiles que s'introdueix en una ferida per recollir la supuració'.

88 atard, 'poques vegades'.

89 ix-li] om. ms. seguim JQ.

90 fer-li-as] feslias ms.

91 l'esperver] l'esperver <al vespre> JQ. 


\section{Marinela Garcia Sempere. El Llibre dels ocells de caça, o Flors de les receptes medicinals per a ocells de caça}

E, si està arufat ne flach de si matex, porta-lo en selva on prenga cabirols. ${ }^{92} \mathrm{E}$ aquí pesca-lo hom del fetge del cabirol mascle calent e del cor; pus sia past ${ }^{93}$ al sol, e, dementre que s'escalferà, de la malaltia guarrà. Ítem, com està arufat, prin la maytat del corter del palurna ${ }^{94}$ e unte'l en such de exens ${ }^{95}$ he fe-li trasglotir. E da-li rata penyada a menyar.

Ítem, més, si à mal de lop, enbolco'l' ${ }^{96}$ dins lo botó de la carn e dona-li soptosament, axí que no se’n puya apersebre.

E deus saber que a conservar sanitat als espervers he ha conservar a les vescositats e les sobrefluhitats, plomades sovén donades maravellosament los valen, e los tolen fastigs ${ }^{97}$ e $1 \mathrm{l}$ recorren e ls fan pus leugés he pus alegres he pus ardits.

Ítem més, si à mal de rampa he tremoló dels peus, la qual a vagades los esdevé, val que hom los do la carn mullada en such d'ortigues e de artemeya.

Ítem, sanch ${ }^{98}$ d'anyell tèbeha, los peus d'aquel fregats, e vin tèbeu en què sien cuytes hortigues, e $\mathrm{n}$ asò li unta lo past. [118r] E, com aquell es farà per aygua ${ }^{99}$ ho per estar en terra, trau such de la eura ${ }^{100}$ he, tebet, unta-li los peus e la carn.

Ítem, caragols blanchs cou he unta'n-li los ${ }^{101}$ peus he fes-lo sagnar en la cuxa.

Si les ales de l'esperver pengen massa, untar-li-les as ab sanch de hoca al sol e péxer-l'as ab la carn de la hoca. Ítem, fes-li tenir les ales alt he unta'l alí ab oli de l'or. ${ }^{102}$ Ecara, si les untes desots les ales ab fel de porch, hi val.

92 cabirol, 'animal de remuc, de la família dels cèrvids, espècie Cervus capreolus, semblant a una cabra, de pelatge rogenc en l'estiu i gris fosc en l'hivern'.

93 past post JQ.

94 palurna] aquest mot és mig esborrat en el ms.

95 exens] xenes ms.

96 En aquesta recepta sembla que hi manca el que s'ha d'embolicar en la carn, que pot ser àloe JQ.

97 fastigs] fastictos fastigs ms.

98 sanch] amb sanch JQ.

99 ayua] ayg ms.

100 eura, 'planta de la família de les araliàcies, de l'espècie Hedera helix'.

101 los] lo ms.

102 l'or lor JQ.

SCRIPTA, Revista internacional de literatura i cultura medieval i moderna, núm. 17 / juny 2021 / pp. 280 - 336 


\section{Marinela Garcia Sempere. El Llibre dels ocells de caça, o Flors de les receptes medicinals per a ocells de caça}

\section{Capítol XIIII. Si l'esperver à sobrehòs}

Si l'esperver à sobrehòs en les cames ho en les juntures, ligua-li àlohe calt desobre, he lexe'l axí estar per un dia he per una nit. Puys, prin fem de guall cuyts en vinagre e tèbeu, posa-lo-li he tengua-ho un dia he una nit.

\section{Capítol xv. Si la pena de l'esperver és trancada}

Si la pena de l'esperver és trancada, serca la rel he trau-la, per so que altra n'i nasca. Puys, prin sanch de grill he, si no $n$ pots aver, prin sanch de una reta qui és dita garex ho rati, [118v] he unta-li'n lo loch, he exirà̀n. Puys possa en lo forat un poch de mel cuyta, axí com diu en lo capítol de les tinyes, e crexeran-li les penes.

E, si les ales accidentalment li pengen per rahó de dolor, prin lo such de la sàlvia ab let de somera he de fembre qui aya encahut VIII dies passats, mescla-ho, e de asò unta-li les ales e lo menyar. En asò matex val cervel de voltor ${ }^{103}$ he de guat al jóvens espervers e als vels.

E, si les ales los penya naturalment, unta-les-li ab such de barbena, ${ }^{104}$ e guarrà.

\section{Capítol xvI. Si l'esperver à màcula ho desfeta en los ulls}

Si los espervers an màcula ho desfeta en los ulls: possa-li del pebre e d'àlohes, tant de la hun com de l'altre mesclat encemps, e $n$ los ulls asò li mit.

Ítem, si és temps que prunells salvatges o arenyons $\mathrm{se}^{105}$ troben, tres gotes del such d'aquels hi metràs, he serà guorit. E diu lo mestre de aquesta art que un rocinyor seu avia màcula en l'uyll e que l'i mès pols de cals viva, enaxí que ab una ploma, subtilment bufant, l’i mès, he fon guarit, per què yo creu que valria contre la màcula de l'esperver.

\section{Capítol XvII. Quant l'esperver à mal en los ronyons [119r]}

Cant l'esperver à mal en los ronyons, poràs-ho conèxer com no pot luny esmirlar. $\mathrm{E}$ val en asò que prengues carn d'om anbalsamada que troba hom en poder dels especiers, e pèls de lebra, he donali'n a menyar ab carn de gat. E fes asò entrò a viII dies, he sens dupta serà deliurat.

103 voltor cadell JQ.

104 barbena, verbena, 'planta verbenàcia, de l'espècie Verbena officinalis'.

$105 \mathrm{se}]$ so ms.

SCRIPTA, Revista internacional de literatura i cultura medieval i moderna, núm. 17 / juny 2021 / pp. 280 - 336 


\section{Marinela Garcia Sempere. El Llibre dels ocells de caça, o Flors de les receptes medicinals per a ocells de caça}

Ítem més, val en asò pólvora de coriandre ${ }^{106}$ en un cor de poll a menyar, he serà sanat.

E deus saber que, com l'esperver ha pedre en los budells, pren la carn ab lo bech, e, mantinent, la gita que no la vol rebre. Adonchs, tu prin un perdal he pex-lo'n e volpen aquella carn en pólvora de girofle. E, l'endemà, dóna-li un colom poch, e, si reté lo past, és garit.

Algunes vegades és senyal en la natura devall que no pot bé esmirlar, per què ${ }^{107}$ per asò pendràs cor de porch e ab asò mescla bleda ${ }^{108}$ tallada ben menut e dona-li'n per tres dies, he serà guarit. $\mathrm{E}$ diu lo mestre d'aquesta art que haquesta malaltia pot hom conèxer a l'esperver tocant davall per la natura ab la mà; e dix-li aquell que qui donava a l'esperver oli de holives en un budell, que lo y fahés trasglotir, que $1 \mathrm{fa}$ mils he pus luny esmirlar. [119v]

\section{Capítol xviII. Com l'esperver à filandres ${ }^{109}$}

Com l'asperver gita ho esmirla cuchs, dóna-li limadura de ferro ab carn de porch.

$\mathrm{E}$, quant volràs ell fer ardit, tin-lo en la mà longament. E dóna-li a hora de tèrcia carn de poll a menyar, una cuxa. Aprés de una hora, fe'l banyar en aygua. Puys, poso'l al sol, hi estigue-y tro que sia axut. E, asò fet, mit-lo en loch escur tro al vespre ${ }^{110}$ que li encenes una lenterna que li crem denant. E, al matí, ruxo'l ab bon vi. Puys, tin-lo un poch al foch. E, asò fet, a cap de viII dies, ve 'n cassar. E, si veus que molt vuylla pendre aucels, gita-l'i, he, si no u requer, no lo y gits. E, quant ell n'aurà pressos, de mantinent péxer-lo'n as, e fer-li'n as pler. He, si no'n vol pendre, retorna'l a la dieta damunt dita tro que $n$ prengue volenter.

Pus avem perlat dels espervers, nesesari és que perlem de les nobleses dels falcons e de molts he diversos altros aucells de rapina. XVIIII. ${ }^{111}[120 \mathrm{r}]$

La noblasa dels falcons és coneguda per lo cap rodon he solla ${ }^{112}$ sobiranitat del cors plana, e que sia lo bech gros e rodó, e bella nefa, lo cors ${ }^{113}$ lonch, e belles espatlles e amples, e les penes delgades e

106 coriandre, celiandre 'planta de la família de les umbel líferes'.

107 perquè] perquè [...] JQ.

108 bleda] seca de porc JQ.

109 filandre, 'cuc paràsit de l'aparat digestiu de certs aucells'.

110 vespre] vespre, <i posa un pany de llana sobre la perxa en què és per a que no es faci mal a les ungles; i tin-lo en la mà des d'hora de vesprés fins al primer son; i llavors posall a la perxa amb el pany col locat a sota com abans i per tot el vespre > JQ.

111 XVIIII] xifra que inclou una altra mà.

112 solla] deu voler dir xolla.

113 cors $]$ colJQ.

SCRIPTA, Revista internacional de literatura i cultura medieval i moderna, núm. 17 / juny 2021 / pp. 280 - 336 


\section{Marinela Garcia Sempere. El Llibre dels ocells de caça, o Flors de les receptes medicinals per a ocells de caça}

soptills, e les costes sien longues, e les cuxes sien curtes e grosses, e que agen. com és jova, los peus blaus e ben aspres, estesos e bells glays e grans.

E deus bé guardar que tot aucell de cassa qualque sia guarts de fum de pegunta cant hom calferà lenya de nau, que no 1 ne pas, ne 1 passeràs en altumpne, que és en varemes, en loch on aya babor de most, cor corrompri ell ${ }^{114}$ e lo cervell que li giraria. E diu lo mestre d'aquesta art que a hell ne morí hu. E més, lo garderàs de tota pols e mayorment en la gran calor. E no 1 metes en cassa nova ni enblancada de cals. E més, lo garde de tota pudor de palla ni de bassa on hom amara li, so és, banyar li.

E, qant lo volràs porgar, porguar-l'as d'àlohe, segons que conexeràs, ho de plomades.

\section{Capítol xx. Qui parla dels ocels qui muden, en especial en aquel any que l'esperver no vol mudar hivàs}

En aquell any que l'esperver no vol mudar hivàs, crema una granota, e de la pólvora de haquella, tu li dona a menyar. E en aso ma-[120v]tex diu un mestre que val pólvora de serp, he un luert cremat e polvoritzat, hi és bo.

\section{Capítol XxI. Com l'aucell no à volentat de pendre aucells}

Com l'aucell no ha volentat de pendre aucells, la qual cossa s'esdevé sovent, per so com és massa gras, és senyal que és massa delicat. Lavors, sostrau-li alcuna pertida del past covinentment. E, com veuràs que pus valent e pus ardit sostendrà en aquella covinent dieta, tu 1 conserva en aquella.

E, com l'esperver ho lo folcó és benyat, guarde’t que no 1 tochs ab la mà.

E, si l'esperver no pot coura la carn que hom li derà, posa-li un gra d'estafisàgria sots la lenga e, de mantinent, la carn que aurà menyada courà.

E deus saber que un canonge, qui avia nom Guido, avia un esperver de vi mudes, lo qual tornà orp, enaxí que no 's veÿa lo past que hom li donava, e pexeren-lo axí com hom pex coloms. ${ }^{115} \mathrm{E}$ durà-li aquella segatat bé VII messos ho VIII, enperò negun senyal de seguetat no li paria en los ulls, ans los avia axí clars com null temps ach. Al qual, aprés moltes medesines que li hach fetes que res no li valgueren, donà-li àlohes en pólvo-[121r] ra, en canditat de un ciuró, envolpat en un troset de carn, e recobrà la vista ans de tres dies. $\mathrm{E}$ de asò matex ${ }^{116}$ poràs donar als hòmens avent aytal malaltia.

114 corrompri ell] corrompiell ms.

115 colomins JQ.

116 de asò matex] de aso matex e aso matex ms. 


\section{Marinela Garcia Sempere. El Llibre dels ocells de caça, o Flors de les receptes medicinals per a ocells de caça}

E diu Gualién que girapiga ${ }^{117}$ val axí matex a reustaurar la vista. Encara deus ${ }^{118}$ saber que aquel matex Guido avia acustumat de untar lo cap de l'esperver ab sobó. ${ }^{119} \mathrm{E}$ dix-me que duptava si era garit per virtut del sabó ho de l'àlohes. Mas a mi és semblant que per la virtut de l'àlohes fos estat garit.

\section{Capítol xxII. Per mudar aucells}

A mudar aucells faràs aquesta aygua: que prengues c caragols e mit-los en un sac de li ho de cànem, he sien trencades les closques de aquels. Puys, penya lo sach al sol e aquella aygua qui degoterà, met-la hom en una empolla. E, com hom donerà a menyar a l'aucell, en aquella aygua sia benyat lo past que hom li darà a menyar.

Ítem, sia la muda bella e blanca, axí com a colom, e prin vi ho vII prunes que hom troba verdes en l'arbre, e cremar-les [121v]as. E, puys, mit-les en l'aygua demunt dita ab lo past. E, com comensarà a gitar los vans, mulla un poch la carn en la dita aygua.

\section{Capítol XXIII. Per reuma o cadarn del comp o de la gola o dels ulls}

Per reuma o cadarn del comp ho de la gola ho dels ulls, prin lart ${ }^{120}$ selat e sech, e rau-lo bé manut en ayguo freda. Puys, ab un bastó mena bé l'aygua tro sia bé espés, quax axí com ayguacuyta, e mesclahi dos grans de clavells de girofla polvoritzats ab lo demunt dit lart; aprés, sia mesclat ab l'aygua he castanyes seques cuytes. Encara, met hom al matí e al vespre pólvora de hos de sípia en los ulls de l'aucell si ls ha panyossos. E asò fasa hom per dos dies ho per tres, enaxí que hom unt lo past tota hora ab les demunt dites cosses.

E, com l'aucell no pot bé esmirlar he fa la fenta a manera de gleda, lavors l'alcell à mal de pedre, la qual axí curaràs: prin vidra ho la rel del morritort salvatge, he trau lo such, e d'aquell such en un budell de galina ligat mit-lo-y per so que 1 such no n'hisqua. E dona-li d'asò a menyar al vespre. E, l'endemà, troberàs en la fenta pedres. [122r]

\section{Capítol XXIIII. Com l'aucell à gota}

Cant l'aucell à gota he té lo peu estret que no 1 pot estendre, trenca-li hom lo cuyro que té sobre los dits he lo tou de la mà de la part darrera. E, puys, de la part jusana depertex lo cuyr ab una ploma. E, puys, hom pren aytant com un gra de pebre d'encens e possar-l'as petit. ${ }^{121}$ E, asò fet, encín aquel

117 girapiga, giripiga, 'sèver sucotrí'.

118 deus] Repetit ms.

119 sobó, llegiu sabó.

120 lart, 'greix'.

121 petit podria ser pertit, amb la manca de la $r$. 


\section{Marinela Garcia Sempere. El Llibre dels ocells de caça, o Flors de les receptes medicinals per a ocells de caça}

encens ab foch en aquell matex loch hon és possat. E, puys, mit-i un poc de holi, puys lexa'l cremar tro que 1 foc entre entrò a l'hos. E, asò fet, apagà l. Puys, exir-n'an moltes gotes de humors, e sarà guarit.

Ítem, a gota de les ales: trasque'n hom una pena qui és dita bisera. Puys, talla hom a manera de sagnia, axí que n'isqua sanch, he sarà guarit.

Ítem, a rinflament que fa, per la qual cossa ha lombrichs ho cuchs: adons, prin fulles de présechs he altretant oli, e mit-ho en un budell de gualina ben levat ab vi. E sia del lonch del cuch e sia ligat lo budell, e da'l-li ensems ab lo past. E, enaxí com esmirlarà, troberàs que giterà cuchs.

E per so ${ }^{122}$ que 1 falcó vol alt, donar-li as carn de hom enbalsemada, aytant com sia pes de viI diners. $[122 v]$ E volerà axí alt com volràs.

Si vols que l'ausell no juch, trau-li una pena qui és sots la coha, en lo loch qui és dit alguarde. Puys, posa-y desús una gota de cera calda.

E, si l'auzell à mal e ha àvol carn en la boca, pose-y desús un poc de agràs, ${ }^{123} \mathrm{e}$, mantinent, serà guarit.

\section{Capítol XXV. Dels linatges dels falcons ${ }^{124}$}

Los linatges dels nobles falcons són aquells ${ }^{125}$ qui són venguts a nós, ço és, que n’i à tres linatges de falcons qui no són bons.

Ítem, n’i à tres qui són mesclats de nobles he no de bons.

Ítem, n’i à un mesclat, lo qual, per so com de tot en tot no és de noble agre, ${ }^{126}$ molt és bo a cassar.

Lo primer linatge de nobles falcons he lo pus noble que sia és aquell que alguns hòmens apellen sacre, e Simacus lo apelle brotany, ${ }^{127}$ e alguns altros lo apellen haeripill, ${ }^{128}$ quax qui vol dir falcó qui ama l'àher. E de asò de sobre avem dit que él ama molt alt volar, e ha en menys-[123r]preu

122 so] so tom $\mathrm{ms}$.

123 agràs, 'suc aspre que es treu de raïms verds i l'empren per amaniment'.

124 Una altra mà ha afegit Primer capitol del linaje dels falcons. En aquest moment comença la traducció del text d'Albert el Gran.

125 aquells] aquells deu JQ, sunt decem AG. Prenem les referències a Albert el Gran o Albert Magne de l'edició de Stadler (1916-20) i les indiquem com AG.

126 agre, 'el lloc on tenen costum d'acudir certs animals'. ignobili parente AG.

127 Llegiu britànic ja que el text font, d'Albert el Gran (AG) diu britannicum.

128 apellen haeripild aelium quasi aërinum falconem AG. Vol dir 'aeròfil' segons JQ.

SCRIPTA, Revista internacional de literatura i cultura medieval i moderna, núm. 17 / juny 2021 / pp. 280 - 336 


\section{Marinela Garcia Sempere. El Llibre dels ocells de caça, o Flors de les receptes medicinals per a ocells de caça}

aquestes preses poques. Aquest aytal falcó ha les cames poques, grosses e plenes de nuus, e pus cruells ungles que àguila, e vista terrible, e los ulls fort flamenchs e declinant-se en color citrina e 'n royor ${ }^{129}$. E à lo cap gran e lo bech molt fort, ${ }^{130}$ e los nus e los plechs de les ales grans he quax tostemps abandonades a volar. E aquest tan solament entre los altres falcons ha la coha un poch longua. Aquest aytal falcó és semblant quax en granesa ha àguila. E sots aquest no vola àguila ne aucell nengú de cassa per pahor que n’an, com, mantinent que ls altros aucells veuen lo sacre, fugen e criden e amagan-se per los arbres espessos e possen-se; ${ }^{131}$ encara enans se lexen pendre ab les mans que no volar per l'àher.

Qui ‘s vol dos falcons sacres volen encemps, tant fort los menerà hom e los domda que sehen en una perxe, e saguexen axí hom com si no sabien estar sinó ab hom. E no és aucell que matinent no l'enderoquen; he no ls basta sol un, mas tots quants ne troben s'enderroquen, e prenen-ne quax los crabits $^{132}$ e $1 \mathrm{ls}$ fenen tots ab les ungles e los trauen los ulls e lo cervel.

Aquests [123v] falcons aytals se nodrexen e s volen nodrir fort delicadament tota hora. E volen menyar cors e cervells freschs ${ }^{133}$ e sans, e altres carns que sien tant fresques que totes sien calentes de la calor natural de la bèstia, he quax mengen aytant com unes grans àguiles.

Aquest linatge de falcons és reyal e longament volador, enaxí que ell seguex la presa de dues ores fins en VI ores, ${ }^{134}$ más mills cassa ab companyó, emperò bé cassa tot sol. $\mathrm{E}$ ama los hòmens he los cans de cassa, e cassa pus valenter com ells hic són presents, axí com si ell se glorificava en ses forces per la presència d'ells.

Aquests falcons se conexen ab lo linatge dels altros falcons en aquelles cosses que avem dites damunt: co és a saber, en les gotes ${ }^{135}$ e ab los senyals de la cara he en sa figura, e en so que fan per lur propietat, e en la veu; la veu d'aquest falcó aytal és espaventable e crida atart. E cové que aquell qui l crida, crit en alta veu e ab la veu que haya bon so, per so com ell vola alt he luny, e cové que 1 loura ${ }^{136}$ sia gran per so que $l$ puxa veure de luny. Emperò, si no y torna tost, no és perhill, com [124r] per si matex sol torna a cassa. E aquest és lo pus primer linatge e lo pus nobla dels falcons.

129 Ex citrino in rubedinem declinantes AG.

130 molt fort fort molt fort $\mathrm{ms}$.

131 ad condensa arborum vel ad terram AG.

132 cabrits] tabrits ms.

133 freschs] fres freschs ms.

134 ores] oros ms.

135 en les gotes e ab los senyals de la cara he en sa figura] tam in guttis faciei cum figura AG.

136 loure, 'menja que es mostrava als ocells de caça per atreure’ls cap al caçador'. Reclamatorium AG. 


\section{Marinela Garcia Sempere. El Llibre dels ocells de caça, o Flors de les receptes medicinals per a ocells de caça}

\section{Capítol XXVI. ${ }^{137}$ Lo segon linatge dells falcons}

Lo segon linatge dels nobles falcons és grifaut. E ha acabada natura de falcó en figura he en color, e 'n asò que pròpiament he $\mathrm{e}^{138}$ hom veu, mas en quenditat ell és mayor que astor e manor que àguila. E és dit grifaut a gera ${ }^{139}$ en latí, que vol aytant dir 'sant' ho 'persegüent' per so com tant longament e tant fort peseguex la presa que és maravella. ${ }^{140} \mathrm{E}$ ha endeny de poca presa, mas tota ora seguex he pren grans aucells, axí com gruhes e sens ${ }^{141}$ e d'altres d'aquests semblants. Aquest aytal és molt bell aucell e no lonch, ${ }^{142}$ segons la faysó de son cors; e ha los nuus ${ }^{143}$ e los plechs de les ales molt covinents e forts; e ha les cames planes e no y ha nuus; ${ }^{144} \mathrm{e}$ ha assats forts ungles, e mayorment les derreres; e cassa tot sol, emperò mills cassa ab altres. Entre los altros falcons ell sol estar tot dret, ab les ales entrecenades. ${ }^{145}$

E, com és en [124v] cassa longuament, seguex la presa. E per asò lo cassador ha hops cavall corrent ab què 1 puxa seguir. E deu aver cans bé adotrinats he ben corrents ${ }^{146}$ con ha enderrocada la presa. Aquest falcó mayorment deu hom adoctrinar he ensenyar que no s'assiga ne ss pos en aygua ab la pressa com sovín és luny del falconer. E per so poria gran dan pendre en l'aygua, e per so no 1 deu hom gitar a la presa com hi ha longueha de aygua, ans lo deu hom retanir fins que ls aucells són fora de la aygua e volen sobre los camps. E, selavós, deu hom gitar lo grifalt de la part de la aygua per so com, per pahor del grifaut, los aucells no gossen tornar a l'ayga; mas, si lo grifaut lexa hom anar de la part dels cams, ${ }^{147}$ lavors los aucells fugen devés l'ayga, e, si són farits, cahen en l'aygua. Lavors lo grifaut, seguint la presa, és malmenat he ha son cors banyat. E, si n'escapa, tot vendrà pesarós ${ }^{148}$ per so com ha mal pres.

137 Capitol XXVI] capito ms. La mà que va posant números als capítols, ara s'adona que es tracta d'una part dels llinatges i deixa de numerar.

138 he] fa he JQ.

139 a gera] a gira JQ, a girando AG.

140 et dicitur gyrofalco a girando quia diu girando acriter praedam insequitur AG.

141 sens] cignos AG.

142 e no lonch] non longa secundum proportionem sui corporis cauda AG.

143 nuиs] petrs nuus ms.

144 nuus] nous ms.

145 entrecenades] bene compositis AG.

146 corrents] coneuts ms., corrents <que l'auxiliin > JQ, velocibus canibus AG.

147 camps] campi AG.

148 pesarós] peraros ms., timidus AG. 


\section{Marinela Garcia Sempere. El Llibre dels ocells de caça, o Flors de les receptes medicinals per a ocells de caça}

Desots grifaut altres aucells no y volen, ni falcons, ni estors, ne milans ${ }^{149}$ atart se mesclen ab ell. Aquest falcó aytal ${ }^{150}$ vol menyars ${ }^{151}$ delicats e que sien pasts ${ }^{152}$ freschs, enaxí que encare ${ }^{153}$ sien calents de la natural calor de la bèstia. E dats-[125r]li delitossos pasts, axí com són aquells pres lo cor, com aquella carn qui està prop lo cor, aquella aytal és anant degerida. Que asò dega axí ésser, asò és senyal manifest que, com ell és salvatge e pren presa, ${ }^{154}$ no trobaran que menuch sinó lo cor, e despuys so qui està aprés lo cor, envers la ala dreta e atart ves la sinestra. Aquest vol menyar aucells que no ${ }^{155}$ sien de calda conprecció, axí com són coloms e pahons salvatges ${ }^{156}$ e altres aucells freschs; de aytal manera [que] ${ }^{157}$ negun linatge de falcons, ne de estors, ne de espervers ${ }^{158}$ no tornen com són salvatges a menyar so que ha lexat a la presa ne so qui $\mathrm{n}^{159}$ roman; ans puys altra veguada, com volen menyar, prenen novella pressa. E asò no fa lo linatge de les àguiles. Encara, que falcó no $s$ possarà sobre carnades a menyar, axí con fan milans he àguiles ${ }^{160}$ he altres aucells.

Donchs, carn fresca tota calenta se tany a grifaut que nex lo salvatge, ans comensa a menyar la presa que ell ha pressa, per so com molt se adelita en menyar sana carn. E per so yo no vull que so que alguns fan, ço és a saber, que trahen a la guallina viva la cuxa ho l'ala, e puys, l'altro jorn, daran de aquella matexa guallina l'altra [125v] ala ho cuxa, he donen-ne al falcó; per tot sert tot l'altre cos de la gualina romanent és ya pudent ho corrunput he és comprés de calor de febre, com febre en tot loch ho cos és ${ }^{161}$ sucitada en genrament ${ }^{162}$ de podrificació. Per so no cové a grifaut, que és aucell delicat, que hom li do pasts sinó ben calents he freschs. ${ }^{163}$

149 milans] aquila $\mathrm{AG}$.

150 aytal es aytal $\mathrm{ms}$.

151 menjars] menjar ms.

152 pasts] pats ms., cibari AG.

153 encare] encare tare ms.

154 com ell és salvatge e pren presa] quando silvester praedam accipit AG. Sembla que el traductor atribueix l'adjectiu a l'ocell i no a la presa.

$155 n o]$ en JQ.

156 pahons salvatges] columba et palumbis AG.

157 que] om. ms.

158 de falcons, ne de estors, ne de espervers] falconum vel asturum vel nisorum AG.

159 qui n] que $n \mathrm{JQ}$.

160 axi con fan milans be àguiles] sicut aquilarum et milvorum genera AG.

161 és] $e$ ms. JQ.

162 en genrament de podrificacio in generatione saniei $\mathrm{AG}$.

163 freschs] frecbs ms.

SCRIPTA, Revista internacional de literatura i cultura medieval i moderna, núm. 17 / juny 2021 / pp. 280 - 336 
Donchs, a bon folcaner se deu estudiar aytant com pot que l'orda de péxer seguesca la natura dels falcons, la qual natura lo grifaut demostra acabadament com és salvatge. E enaxí los grifauts he los altres profiteran he crexeran en lur forsa natural. E, si d'altre guissa se fa, poch a poch lo falcó s'enmalaltex he mor. Aquests dos linatges de falcons damunt dits són primers he pus nobles de tots aquells qui són venguts desà entre nos.

\section{Capítol XxvıI. ${ }^{164}$ Lo terç linatge dels falcons}

Lo linatge dels falcons montarins és lo terç en noblesa de natura. Aquest aytal linatge de falcons montarins és breu he espès fort en lo cors, especialment ha la coha breu he fort espessa de les plomes de la coha agudes; e ha lo pit ${ }^{165}$ molt rodon ${ }^{166}$ e gran; e ha les cames forts he breus, ha esguart [126r] de la canditat de son cors; e ha los peus plens de nuus e ha forts ungles, e ha en costuma que fort sovén s'esguarda sos peus; e ha color de cendre en la esquena he en la ala de sobre. E haquella color, segons la qual profita ${ }^{167}$ per mudament de les plomes ho de les penes, cascun any és pus clara e més se descolorex, avent en si una poca varietat fosca.

Aquest linatge de falcons és faréstech e de males costumes he és molt hirós. E per so no troba hom falconer qui, de ple en ple, sàpia les sues costumes. E per so és manament de Opotolomeu, rey de Egipta, que atart lo tenga hom en la mà sinó en l'alba he en temps de cassa, mas les altres hores lo tenga hom en una cambre molt escura, e en aquella encena hom dues ho tres vegades foch clar; e no y aya fum, e no 1 tenga hom en la mà sinó a les dites hores, sinó aytant com hom li darà a menyar, com per asò s'amensarà per lo benifici que 1 folconer li fa, e lexa sa hira. E, con se harihex, no li deu molt contrestar lo folconer, com per so més s'ahirex.

Aquest linatge de falcons bé és axí aspre com un estor, jatsia asò que sia molt pus breu, he ha peus fort descolorits, e ha les cames quax totes plenes d'escata. Aquest és aquell linatge de folcons que mayorment se endenyen com la [126v] presa li escapa, axí que, a vegades, nafre aquell qui l'apella en lo cap ho per la cara, ho nafre la cara del cavall que lo falconer cavalca o, ha vegades, nafra los cans o, ha vagades, la un dels dos falcons pren l'altre. E per so cové ${ }^{168}$ al falconer aver gran pasiènsia en aquest cas, e que no li contrast ni li’n fassa res aparès entrò que lo coratge del falcó aya oblidada sa hira e que s'asuauga. ${ }^{169} \mathrm{E}$, si per ventura lo falcó muntarí no vania a lloure com hom lo apella, no cal aver a $\mathrm{a}^{170}$ hom gran ància, mas que hom se guart que altri no $\mathrm{l}$ prengua, car, quant la falonia li serà passada, ell se retornarà per si matex a cassa del falconer.

\footnotetext{
164 XXVII] om. ms.

165 lo pit los pits ms.

166 rodon] rodons ms. amb la $s$ cancel lada.

167 profita] proficit AG.

168 cové] cové aver ms.

169 asuanga] asuanga ms.

170 a] $\{a\} \mathrm{ms}$.
}

SCRIPTA, Revista internacional de literatura i cultura medieval i moderna, núm. 17 / juny 2021 / pp. 280 - 336 ISSN: 2340-4841 · doi:10.7203/SCRIPTA.17.20915 


\section{Marinela Garcia Sempere. El Llibre dels ocells de caça, o Flors de les receptes medicinals per a ocells de caça}

Mas gens per aquestes costumes aytals hom no deu dessamar aquests falcons, com meravellossament són abrivats e prenen grans presons. Enaxí que, a vaguades, avessen-sa he maten l'àguila. Segons que diu Obcolomeu, savi falconer molt se deu guardar que no git a forts aucells sovint que sien molts pus poderossos que ells, per so com la calentura ${ }^{171}$ de aquels, si serà ascalfada, si matex en dexopta ${ }^{172}$ enderoca $\mathrm{n}$ mort. Aytal cassos an ya vists en les muntanyes alsguns nostros companyons. Una veguada s'esdevench que un $[127 \mathrm{r}]$ falcó montarí se levà de una roca he encalsà una perdiu $\mathrm{e}^{173}$ tolch-la, ${ }^{174} \mathrm{al}^{175}$ montarí fon endanyat de aquesta cossa he eforsave's axí com podia que la li tolgués; ${ }^{176}$ mas, com molt hi agués punyat ho trebellat he no pogués acabar sa intensió, a la per fi muntà fort alt he puys devallà fortment sobre l'àguila, enaxí que li donà aytal colp al cap que si mateix aucís e la àguila. Donchs, apar que molt se deu hom guardar de fer hiréxer lo falcó muntarí.

D’aquests falcons aytals se troben més que dels damunt dits altros; ${ }^{177}$ e maravellosament haquests falcons aytals se alegren en lur ferir; e esdevén-se que sovín atroba hom del linatge de aquests falcons a qui no abasta a nafrar un aucell a l'aendorroquar, ans an glòria e bon saber com molts ne enderroquen. A vegades aquests falcons aytals se adeliten tant en lur ferir que ha ells oblida lur menyar, e asò per la crueltat de la ocasió que fan. Aquestes cosses damunt dites basten dels falcons montarins.

\section{Capítol xxviII. ${ }^{178}$ Del quart linatge dels falcons}

Lo linatge del falcó, qui és dit [127v] palagrí, és lo IIII linatge en la noblesa dels falcons. Ell és apellat pelegrí per dos rahons, de les quals la primera és vera com tostemps fa pelegrinatge de una terra en altre, e quax vola per totes terres. La segona és més segons la opanió dels falconers, que diuhen que per so à nom palegrí com hom no sap ne pot atrobar son niu, ans lo pren hom molt luny dellà hon nex. La una $\mathrm{i}^{179}$ altra rahó he yo hoÿda dir a molt bon folconer que avie ${ }^{180}$ abitat

171 calentura] caentura ms.

172 dexopta, 'de sobte'.

173 e] e <una àguila contra (o davant de) la qual la damunt dita perdiu volà, la prengué i> JQ.

174 tolch-la] tolse tolch-la ms.

175 al] i elJQ.

176 Una veguada ... tolgués] Falcone enim montanario de rupe veniente, praedamque in sequente avem quae perdix vocatur, aquila contra quam praedicat perdix volavit, paedam praeripuit, ad quam rem montanarius falco impatientia iniuriae stimulatus a praedicta aquila praedam praeraptam nitebatur accipere AG.

177 altros], altros < dos> JQ, praeinducta duo AG.

178 ХХИІІІ] om. ms.

179 i] om. ms.

180 avie] avien $\mathrm{ms}$.

SCRIPTA, Revista internacional de literatura i cultura medieval i moderna, núm. 17 / juny 2021 / pp. 280 - 336 ISSN: 2340-4841 · doi:10.7203/SCRIPTA.17.20915 
lonch de temps en un loch erm, en unes muntanyes molt altes. Aquest falconer deÿa que aquests falcons que nosaltros ${ }^{181}$ apellam palagrins, que fan lurs ${ }^{182}$ nius en unes altes penyes de muntanyes, e que hom null temps no atrobaria lur niu si donchs no muntaven sus alt ${ }^{183}$ al cap de la penya, e que agués una corda de CL passes ho de CC ho de CCC, e encara seria una inpossible cossa que axí pogués om atrobar lo niu de aquells. E assò és per la gran lunyadessa ho per la gran aspresa de roques. E, per aquesta grevetat, deỹa que era venguda aquesta opanió que hom diu que hom no sap on se fan niu $^{184}$ aquests falcons aytals. Aquest falconer aytal deÿa que ell avia vist moltes veguades que 1 prim e lo tersol ${ }^{185}$ pares aportaven a menyar [128r] a lurs fills en lurs lochs damunt dits de les penyes e de les roques. Encara deỹa que aquests falcons aytals an en costuma que $l$ para e la mara, com los fills an conplida hedat que bé poden volar, giten ells del loch e de la lur abitasió, e asò fa con a si se atraen ${ }^{186}$ pochs aucells. E per so los falcons jóvens venen als lochs plans, en los quals à molts aucells e volen per les terres con no han ${ }^{187}$ certes abitasions.

E yo n'é vists pendre en certes maneres, e lo demunt dit ermità falconer dix a mi la terça ${ }^{188}$ manera. En una manera quax cominal en totes terres són presos axí: que l filat és estés axí en tal manera que ab una corda ab la qual om ligua un laneret roig, ${ }^{189}$ lo qual les gens apellen suomen. ${ }^{190} \mathrm{E}$ a la corda qui penya és liguada una altra cossa estessa on à un alcell; axí, com lo parador tira e sacut la corda estesa par que el laner seguesca l'aucel ${ }^{191}$ e que $l$ vulla pendre. E aquesta corda deu hom menar sovén perquè lo folcó palagrí, qui per ventura passa aquèn, veya l'ocell e que 1 vulla tolra al lener, $\mathrm{e}^{192}$ que, axí enganat, caya en lo filat.

181 nosaltros] la segona $o$ corregida sobre una $e$.

182 lurs] lur ms.

183 alt Repetit ms.

184 niv] to niu $\mathrm{ms}$.

185 terçol, 'tercer. Es deia especialment dels ocells de presa mascles (astor terçol, falcó terçol, etc.), car hi havia la creença que el tercer ocell de la nierada era mascle’.

186 atraen] atroben JQ, inveniuntur AG,

187 han] han $\mathrm{ms}$.

188 terça] certa ms., tertium modum AG.

189 laneret roig rubeus lanarius AG.

190 suomen] sweimerius AG.

191 l'aucel] la l'aucel ms.

$192 e] e<$ davalli fortament, $i>\mathrm{JQ}$, in impetu descendit AG. 
Enperò, yo ${ }^{193}$ he viste altre manera millor. Hom fa un bastiment de $\mathrm{e}^{194}$ fusts a manera de creu, e sobre los estrems d'aquells altres dos fusts són encorbats a mig sercle, axí que los estrems [128v] dels mig cercles són ficats als estrems del fust de la creu. E entre aquests quarts dels archs dels cercles, altres són encorbats als lochs on són tallats los migs cercles, e són ficats avall en los fusts dels angles del coll de la creu dentrò que la un fust no 's luny de l'altre sinó tres ho IIII dits. E, dentrò que las ${ }^{195}$ és complit de cascú dels fusts, de damunt entrò avall en los fusts dels angles del tall de la creu, axí com demunt és dit. Aquest vaxell ${ }^{196}$ sia fet de alt de vII peus ho de viII, e de ample de $\mathrm{v}$ ho de vi. E en aquell fassa hom un cava ${ }^{197}$ de vi peus d'alt e de IIII d'ample, enaxí que los costats dels vaxels se lunyen entre si de un peu com la un és en l'altre. E dedins aya fusts a manera de traus ${ }^{198}$ sobre si ordonats de davall entrò de sobre. E aya dins VI ho vII aucells, com aquells contínuament munteran e devallaran en los traus. E tot asò és afigurat sens moure sobre mur ho sobre castell ho sobre porta ho sobre camps ${ }^{199}$ desliure; cor, ladonchs, lo falcó pelegrí, qui passa, veu los aucels e, volent aquels pendre, roman pres en lo las. $\mathrm{E}$ ya avem vists pendre en aquesta manera molts bons falcons, mas l'armità no dix altre cossa mas que fos possat un aucell menys del laner davant lo filat, com lo falcó és molt cobeyós aucell e ell matex trebuca's ${ }^{200}$ en lo filat. En aquesta manera [129r] deÿa que cascun any prenia dels damunts dits falcons.

Aquest falcó aytal, qui comunament és estat quax en totes terres, és de manor quantitat que falcó montarí, he ha curta coha e longues ales e gros cap e longues cuxes e breu cama, he aya les cames plenes de nuus, que millor n'és. E deu aver les cames blanches e los peus, e és de bones costumes con bé és nodrit. D’altre guisa, la sua presa és axí com cominalment. ${ }^{201} \mathrm{E}$, si aquest falcó aytal és per lo folconer fet bé abrivat, ell pendrà la austarda e a vagades la grua. E asò és la sobiranitat del seu abrivament. D’aquests aucells basta açò que n'avem dit, so és, dels falcons pelegrins.

193 yo] repetit ms.

$194 d e] d e<d o s>$ JQ, duorum AG.

195 las, laqueis AG.

196 vaxell] vas AG.

197 cava] cova JQ, cavea AG.

198 traus] trabium AG.

199 sobre camps] en camps JQ.

200 trebuca's] praecipitat $A G$.

201 cominalment cominalment <l'ànet> JQ, Anas autem ut communiter est praeda sua AG. 


\section{Marinela Garcia Sempere. El Llibre dels ocells de caça, o Flors de les receptes medicinals per a ocells de caça}

\section{Capítol xxix. ${ }^{202}$ Lo v linatge dels falcons}

Lo v linatge dels falcons nobles és gilbós, lo qual lo dit ermità apellà, e mostrà'm ha mi tres falcons d'aquests molt bons, los quals avia ab si; e dix que molts d'altres n'avia vists de bons.

Aquests ${ }^{203}$ falcons an lo cors de poca canditat, mas és de maravellossa virtut e és fort abrivat he à gran noblesa de valor com saguex la presa. La sua granesa pot ésser de quanditat de l'esperver $[129 \mathrm{v}]$ e ha en cara gota ${ }^{204}$ ho senyals, axí com falcó pelegrí. E, axí com los altres linatges de falcons, ell és apellat gilbós per so com, per la brevetat del seu coll, lo seu cap par apenes denant los nuus o ls plechs de les sues ales com les té entrecruades. E ell ha lo cap gran ha esgart de son cors, so és, de la canditat, e lo bech molt breu he redon, e les ales fort longues, e la coha breu, e les cuxes forts, he les cames longues un poch ha esguart de la messura dels altres seus membres, he à-les plenes d'escata' de cerps ho de luerts. ${ }^{205} \mathrm{E}$ ha los peus plens de nuus en ${ }^{206}$ los artells ${ }^{207}$ dels dits, mayorment de la part de dins de la planta dels peus. E ha los ulls flamenchs e ardents. E ha color d'altres falcons qui són apellats pelegrí. E lo seu cap en alt, so és, en lo seu test, ben pla, en la part derrera del cap. ${ }^{208}$

Aquest aytal pot hom amesadar ${ }^{209}$ leugerament, e ha en si bones costumes, e fa son niu en altes penes de roca, axí com los pelegrins. Aquest falcó aytal ha tan gran ardiment he ten gran noblesa que ell enderroca e pren les hoques salvatges he ahustardes he grues. E hés falcó qui vola molt cuytossament he monta molt alt, tant que a penes lo pot hom vesser. A quest falcó no [130r] li basta que enderroch un aucell, ans ne nafre e n'enderroca molts, mas vol aver molts companyons a la cassa, per so com ell és poch he los aucels que pren e enderroca són grans.

Lo demunt dit falconer recomptà a mi que a hom deu remembrar lo linatge dels damunts dits falcons. Ell recomptava que avia vanuts tres falcons de aquests aytals a un baró ho senyor de senyera, los quals, mentre aquest ermità los portava ab si per so que 1 s esprovàs, ell atrobà hoques salvatges blanques, e lexà anar los falcons e les oques muntaren e volaren molt alt. E los ${ }^{210}$ falcons que ell avia aviats trespessaren en puyant les oques, en tant que no y ach negun qui ls pogués vaher. Aprés, com lo noble baró se plengués dels falcons que ell avia perduts, ell e sos companyons

202 XXIX] om. ms.

203 Aquests] aquest ms.

204 gota] guttas AG.

205 luerts] lacertarum AG. lluert, 'sauri de l'espècie Lacerta ocellata'.

$206 e n]$ e ms.

207 artells] ucells ms., artells JQ, articulis AG.

208 en la part derrera del cap] Et retro in capite non prominens AG.

209 amesadar probablement vol dir amensadar.

210 los] los $<$ tres $>$ JQ.

SCRIPTA, Revista internacional de literatura i cultura medieval i moderna, núm. 17 / juny 2021 / pp. 280 - 336 ISSN: 2340-4841 · doi:10.7203/SCRIPTA.17.20915 


\section{Marinela Garcia Sempere. El Llibre dels ocells de caça, o Flors de les receptes medicinals per a ocells de caça}

comensaren les hoques a vaher caura entorn d'ells, qui eren nafrades molt fortment, e trobarenne més de xx qui foren cahudes; e, a la per fi, ells cridaren los falcons he ells vengueren tantost al loure. Totes, emperò, les hoques eren nafrades mortalment, axí com si hom les fanés ${ }^{211}$ ab coltell per mig del cors. E aquesta és la rahó com aquests falcons aytals, axí com los altros linatges, com devallen, no feren mantinent, mas ab lo $[130 \mathrm{v}]$ devallar ells comencen altre vegada a muntar, e, lavors, ells feren ab la darrera ungla, que 's possen de lonch dels pits, ${ }^{212}$ e per so ell fa longa nafre e mortal. E sovén feren tan fort que 's trenquen les ungles he nafren ells mateix e aucien.

Aquest linatge de falcons és que quax totes hores és comú sens àls a volar, ${ }^{213}$ e lo seu ardiment és mayor que la suha forsa, e vol menyar fort fresques carns, enaxí que encara respir de la vidal calor, e ladonchs molt li profiten. Si aytal falcó menge les altres carns, guart-se bé lo falconer que sien carns leugeres, axí com de capons, he aquelles menuch fresques ho almenys que no puden. E fassa les fresques en aygua freda, com los aucells de cassa an lo ventrell fort feble, e per so tost giten lo past per una poca de ocassió e giten lo que no és digest ho cuyt en lo ventrell, e, mayorment, con són pasts de greus carns, com aquella torna tost en putrefecció.

Aquest linatge de falcons se vol aportar longament e matí e a vespre en la mà de l'hom, cor, quant à acostumada la mà de l'hom, pus volenter hi torna. Aquestes cosses que avem dites basten quant és dels falcons gilbosos.

\section{Capítol xxx. ${ }^{214}$ Del vi ${ }^{\mathrm{è}}$ grau del linatge dells falcons}

Lo viè grau del linatge dels falcons e la noblessa possa $\mathrm{n}^{215}$ lo falcó negre. Ell és pus bru ${ }^{216}$ un poch que ls altres falcons, ${ }^{217}$ mas semblant és a palagrí en to-[131r]tes cosses, jatsia asò qu él sia desemblant en color, com en la esquena e sobre les ales; e n la coha ha una foscor negre, e ha tot engir una escuredat he un fosc escoloriment; ${ }^{218}$ e ha les cames e les ungles e lo bec axí com a

211 fanés] fissi essent AG. Deu tractar-se del verb fényer.

212 que spossen de lonch dels pits] Ante pectus disposita AG.

213 Aquest linatge ... volar] Hoc etiam genus falconis est quod semper quasi ad volandum alas exserit AG.

$214 \mathrm{xXX}] \mathrm{om} . \mathrm{ms}$.

215 possa $n]$ possidet AG.

$216 b r u]$ br $<e>n$ JQ, brevior AG.

217 falcons] falcons <pelegrins> JQ, falcone peregrino AG.

218 escoloriment, 'descoloriment'.

SCRIPTA, Revista internacional de literatura i cultura medieval i moderna, núm. 17 / juny 2021 / pp. 280 - 336 ISSN: 2340-4841 · doi:10.7203/SCRIPTA.17.20915 
pelegrí. ${ }^{219}$ Aquest falcó aytal se acosta molt a la forma de un aucell qui és apellat bussarí, ${ }^{220}$ del qual avem feta mensió damunt en lo capill. ${ }^{221}$

Frederich, enperador, saguint lo dit de Guillem rey i $\mathrm{i}^{222}$ de Roger falconer, dix que aquest falcó aytal primerament fo vist en les muntanyes de la quarta regihó del món que són dites Gelbohè; e d'aquells, com lo para he la mare, so és, lo tersol he lo prim, n'agueren gitats los jóvens falcons d'ells vengueren en les muntanyes de la Cicília, e haxí aquest linatge s'escanpà per Lonbardia, qui és dita Hitàlia. E d'aquests ha en unes muntanyes qui s'apellen Alpes hi en les muntanyes de Pirenna, e són venguts en Germàniha, jatsia que encara n’i aya pochs. ${ }^{223}$

Aquests falcons aytals són de nodriment ${ }^{224}$ de pelegrins, e són de complecció de colèrich, so és, que per adust ${ }^{225}$ de la calor de terra colèrica se muda en les penes, e per so són negres; e, com aquests an gran adat d'anys, ells tornen un poch blanchs. E asò se pot provar per so com ells són pus negres en les regihons caldes ${ }^{226}$ que aquells qui nexen entre nos. Per so en los lochs caldes [131v] la sament de l'hou és cuyta en forts calor, ${ }^{227}$ e per so que hix de aquell molt torna negre. Mas, en les fredes regions, la sament de l'hou à en si més aygua e més de omeditat que dels altres, e hés rahó de blancor; e, con n'i a migenserament, és rahó de blancor; e, com n’i a miyanserament, és rahó de varietat, so és, que és quax vayre.

Com dues cosses sien per què nos conexem ${ }^{228}$ les cosses de defora, so és, ${ }^{229}$ figura e color, e la figura més demostro la formetat ${ }^{230}$ he la diferència de la espècia que la color; cor nos avem vistes ya nèxer blanques les cornelles e los corps atresí, com abiten en ${ }^{231}$ lochs frets. Emperò, la figura dels corps

219 Aquesta primera part del capítol éstà resumida en relació amb AG.

220 bussari] butherius AG.

221 capill deu voler dir capitol, in antehabitia AG.

222 i] om. ms.

223 AG afig Gelboe, Salaminae Asiae montana.

224 nodriment nodriment $<i$ ardiment $>$ JQ, nutriturae et audaciae AG.

225 adust, 'sec, àrid'.

226 caldes] que altres ms., calidis AG.

227 calor] color ms., calore AG.

228 nos conexem] nos covexen ms. consideramus AG.

229 és] es es ms.

230 formetat conformitatem AG.

231 en] en en ms.

SCRIPTA, Revista internacional de literatura i cultura medieval i moderna, núm. 17 / juny 2021 / pp. 280 - 336 ISSN: 2340-4841 · doi:10.7203/SCRIPTA.17.20915 


\section{Marinela Garcia Sempere. El Llibre dels ocells de caça, o Flors de les receptes medicinals per a ocells de caça}

demostra belle $e^{232}$ espècia de les cornilles ab aquella dels corps, e qual és la una e qual és l'altre. E per asò $^{233}$ aquell linatge de falcons és vist molt ésser semblant ${ }^{234}$ al linatge dels pelegrins, jatsia asò que agen diferència en la color. E, mayorment —axí com és dit demunt— en haquest linatge lo pare ne la mare constreyen peregrinar lurs fills e haxir del loch de lur generació. Aquestes coses basta ara que avem dites dels falcons qui són dits negres.

\section{Capítol Xxxi. ${ }^{235}$ Del vir linatge dels falcons}

$[132 r]^{236}$ Lo viı̀ linatge dels falcons hés lo falcó blanch, que ve de la part de tremuntana e de la mar Mayor, de les regions de Noruega e de Suènia e de Estònia e dels boschs e de les muntanyes de Finesterra. ${ }^{237}$ Aquest falcó aytal és axí vayr ${ }^{238}$ en blancor com aquell que avem dit $^{239}$ denant, qui és negre. La rahó de la blancor d'aquest mayorment és per lo fret e la humiditat de la aygua ${ }^{240}$ en què nex; e en l'asquena e en les ales és un poch blanch, mas en los altres lochs ha gotes ho senyals molt blanchs, e an atresí altres senyals un poch descolorits. Aquest falcó és mayor en cantitat que pelegrí e acoste's molt a la semblansa del laner, ${ }^{241}$ qui vola per los camps e aguayta les rates.

Alcuns falconers an dit que aquest falcó aytal que fon primerament nat de falcó pelegrí e de laner blanch, jatsia asò que no sia ver com lo abrivament d'él ho demostre. Aquest falcó aytal és molt abrivat he bo e no defall de natura de falcó en naguna cossa, ${ }^{242}$ ne no ha neguna cossa de les costumes del laner; cor, quant ell és muntat alt per cassar, no està ab les ales sostspesses, axí com fa la laner, mas encontinent fer axí com lo falcó.

La suha figura demostra ab los peus e en les ungles e en lo bech e en tot lo cors natura de falcó, jatsesia asò que aya les cames [132v] pus groces e amb més de nuus que lo falcó negre. E asò esdevé a ell per la complecció més humida, que més complex e engruxa les cames d'aquell que les cames de aquell qui per sa complecció és sech e colèrich.

232 belle] vere $\mathrm{AG}$.

233 asò] so asò ms.

234 és vist molt ésser semblant] es vist molt esser semblant esser ms.

235 XXXI] om. ms.

236 En aquest foli la part corresponent al recto apareix en el verso i a l'inrevés.

237 de Finesterra] finitimis AG.

238 vayr, 'vari', in varietate AG.

239 dit dit que ms.

240 aygua] habitationis AG.

241 laner] laner <blanc> JQ, lanarii albi AG.

242 cossa] cassa ms.

SCRIPTA, Revista internacional de literatura i cultura medieval i moderna, núm. 17 / juny 2021 / pp. 280 - 336 ISSN: 2340-4841 · doi:10.7203/SCRIPTA.17.20915 
Mas que aquest falcó perhegue que degua ésser menys valedor ${ }^{243}$ per lo fret e per la humor de la conplecció, asò no és de tot en tot bastant senyal com la virtut de tota cossa és multiplicada per la quentitat de sobreha ${ }^{244} \mathrm{com}$ la natural cantitat no sobrepuya los térmens de la canditat natural. E, per asò, aquest falcó és de mayor virtut que 1 falcó negre, e per lo confiament de la virtut qui és en ell pren mayor abrivament; e, si no és tant valedor ${ }^{245}$ con lo negre, més adurar ${ }^{246}$ com se saguex los aucells que no fa lo negre, e asò és sobirana bonessa en lo folcó.

Los cossos foschs són calts e hirosos ho hoberts, e tost vaporen e hixen de lurs espirits, que són senyals e rahons de virtuts e, ladonchs, són lasats e dibilitats, jatssia essò que sien lonchs per natura; mas los membres blanchs an les carns calcades, ${ }^{247}$ cor són molt humits e són de moltes esperits. Aquests aytals per lo costrehiment e lo calcament ${ }^{248}$ de lurs carns, con no laboran tost, venen en distrucsió, e, per asò, és molt en trabal. Enperhò la complacció humida de la part de dins git en brahons $^{249}$ e nius ${ }^{250}$ e calor, e aquella que 's fa per moviment no lexa emdurehir los nirvis ne los branhons, e per [133r] asò longament romanen movibles he covinens a volar. E, quant aquestes cosses an, los falcons blanchs recobren so que no par que sien tant bons con los falcons negres.

Aquestes cosses damunt dites basten ara dels falcons blanchs com quax en naguna cosa no s luyan de lur cassar ne de lur nodriment dels ${ }^{251}$ altres falcons.

\section{Capítol xxxir. ${ }^{252}$ Del viIIè linatge dels falcons}

Lo VIII linatge dels falcons és haquell qui és apellat roig e lo antich nom; no que ${ }^{253}$ de tot en tot sia roig, mas car los senyals qui en los altros són blanchs an aquests són roigs e negres, axí com en los altres són entremesclats. Aquest falcò aytal no par roig en le asquena ne en les ales, sinó con estén les ales, com, ladonchs, so qui hi és fosch apar roig.

243 valedor] velox AG.

244 sobreha] quantitati subiecti AG.

245 valedor] velox AG.

246 adurar, 'resistir', durat AG.

247 calcades] calçades JQ, consertas AG.

248 calcament consertionem AG.

249 braó, 'part del braç compresa entre l'espatla i el colze'.

250 nims nervos AG.

251 dels dal ms.

252 XXXII] om. ms.

253 no que que ms., non quod AG.

SCRIPTA, Revista internacional de literatura i cultura medieval i moderna, núm. 17 / juny 2021 / pp. 280 - 336 ISSN: 2340-4841 ·doi:10.7203/SCRIPTA.17.20915 
Alguns escriviren aquell linatge de falcons falsament, e dixeren que aquests aytals avien natura borda, con deÿen que aquests falcons aytals eren nats de laner roig e de falcó. Mas asò no deu hom dir per so com no ha nenguna confermetat sinó de color ab lo lener; mas, mayorment per rahó de la royor e de la color en lo superfícies de son cors qui hinfla, ${ }^{254}$ lo fa més humit, e per asò és ${ }^{255}$ [133v] gitat del linatge de les penes dels altres falcons; e so fa la migana complecció entre blanca e negre. Axí com en les altres cosses, enaxí que en aquell linatge no ve la natura d'aquest terme estrem, la qual és raó d'orda, sinó per los migs; e per so aquesta migenseria se cové a aquell linatge de falcons. Cor les altres ${ }^{256}$ colors mityanseres no 's covenen al linatge dels falcons, per so com la color vert e blava e groga; e aquestes aytals devalen de la natura abrivada e valent, car la color és mostrement de la cossa, exí com apar en les orines en la color vert ab demostrada fradeha d'aygua; la color blava demostre complecció de bledes e astenehida $;{ }^{257}$ la color groga demostre còlera corrompent. E yatsia asò que dues d'equestes colors sien atrobades en los aucells e la tersa en lo pahó; enperò, no és covinent a brivament ne a udàsia.

Aquest falcó aytal no és gran, ans és un poch manor que $l$ pelegrí, mas à forts mans e forts ungles e fort bech; e és fort valador, so és a dir, que tost se cuyta an son volar, mas no adura molt. E molt lo domdo hom bé, e milor con és de dos ho tres mudes. Mas no viu tant com los altres, e per asò cové que hom lo nodresca e que li don hom a menyar pasts freschs, enaxí que encara sien calens e que respiren per la calor vidal, e que no li deu ${ }^{258}$ hom massa dar a menyar [134r] ne moltes veguades lo dia, mas a matí e a vespre. Encara cové que hom lo guart molt d'aquelles cosses qui alcexen ${ }^{259}$ e muden la sua complecció com laugerament se destrempen; ne cové que hom lo constrenga ultra masura a cassar, com la complecció roige tost és agrauyad e vensuda per treball, jatsia que en lo comensament sia abrivada. E, per asò, la hedat acostant, un poc temprat l'enflamat humit fa molt gran ayuda en ${ }^{260}$ aquesta complecció, e mayorment lo mudament de les penes d'ella, com la pena ho ploma qui axí és roge, és frèvols e molla e no sosté longuament a volar bé. Totes aquestes cosses se deu pensar lo bon folconer e lo savi.

E basta asò dit del falcó roig.

254 binfla] binfla $<$ ma $>$ JQ, inflamat AG.

255 per assò és] per asso es e per so ms.

256 altres] altres altres $\mathrm{ms}$.

257 astenehida] potser astrenehida. Paraula de difícil lectura.

258 deu] do ms.

259 alcexen] o altexen, alterantibus AG.

$260 e n] e \mathrm{~ms}$.

SCRIPTA, Revista internacional de literatura i cultura medieval i moderna, núm. 17 / juny 2021 / pp. 280 - 336 ISSN: 2340-4841 · doi:10.7203/SCRIPTA.17.20915 


\section{Marinela Garcia Sempere. El Llibre dels ocells de caça, o Flors de les receptes medicinals per a ocells de caça}

\section{Capítol xxxıII. ${ }^{261}$ Del viıİè ${ }^{262}$ linatge dels falcons}

Lo vinIè linatge dels falcons, qui ya 's declina de la quantitat ${ }^{263}$ dels nobles falcons, és aquell qui à los peus blaus e de color d'ezur, lo qual és semblant en cantitat e en figura al ${ }^{264}$ folcó pelegrí, mas la esquena d'aquest ne les ales no són tan negres, e ha los pits pus blanchs que lo falcó pelegrí, e no à tant longues ales com aquell, mas la $[134 \mathrm{v}]$ coha à un poch pus longua, e la sua veu és pus aguda per so com és de pus flaumàtica complecció. És molt mans $\mathrm{e}^{265}$ abrivat e ardit en pendre presa com pelegrí, cor aquels falcons qui an los peus de color d'assur tart prenen mayors ocells que piga ho cornella, mas los pelegrins e los altres falcons mayors prenen qual aucell vos vullats.

Esdeven-se que, com aquel qui à los peus d'assur s'eleva en alt per ferir abrivadament, ell comensa estar per pahor ab les ales sospesses, e no ve axí com deu abrivadament sobre la pressa. E aquesta propietat ha per sa natura, mas per l'ajuda e per la dessiplina de l'hom qui li ajuda sovín pren mayor abrivament, mas no ve axí con falcó.

Dels hocells de cassa és axí com de la fortelesa dels cavallers, com molts cavallers són per lur natura e per lur conplecció febles e volpenys, ${ }^{266}$ emperò per saber de cavalleria e per hús de junta que fan sovén, he per esprovament de esvahyr lurs enemichs e de esperar he de farir he de aguaytar, he per fiansa de lurs companyons que ls ajuden moltes de vagades e sovén [135r] fan nobles fets victoriosos. Atresí és d'aquest linatge de falcons, cor jatsia que sia poruch per natura, emperò per la esperiènsia que pren del savi falconer e per l'ús ${ }^{267}$ de enderrocar e de retanir los hocells, e per fiansa del falconer qui li és de prop és fet millor he pus abrivat que no és per la suha natura. L'esperver pren axí matex aquest abrivament per rahó d'aquell qui 1 porta, e per asò ell pren moltes vegades ocells qui són molt pus grans he pus forts que ell.

No és naguna maravella, donchs, $\mathrm{si}^{268}$ lo linatge dels lanés prenen per aquesta manera e enderroquen los ocells, los quals ${ }^{269}$ an tan gran pahor naturalment e ten gran cohardia que no prenen ${ }^{270}$ sinó

261 XXXIII] om. ms.

262 VIIIѐ] VIIIIo ms. I també en la primera línia.

263 quantitat qualitate AG.

264 al a al ms.

265 mans e] minor in AG.

266 volpeny] potser volpell, 'covard, poruc'.

267 l'ús] lurs ms.

268 si] $s i<a m b>$ JQ.

269 quals $]$ quals <laners> JQ.

270 prenen] pren ms.

SCRIPTA, Revista internacional de literatura i cultura medieval i moderna, núm. 17 / juny 2021 / pp. 280 - 336 ISSN: 2340-4841 · doi:10.7203/SCRIPTA.17.20915 


\section{Marinela Garcia Sempere. El Llibre dels ocells de caça, o Flors de les receptes medicinals per a ocells de caça}

rates, he, a vagades, los aucells con són hexits del niu, que no poden volar, ho con són en lo niu he corren per la terra. En aquella manera los aucells poruchs ${ }^{271}$ són fets abrivats per dissiplina, a la derreria ho manifestarà.

\section{Capítol xxxxiv. ${ }^{272}$ Del x linatge e lo darrer dels falcons}

Lo xè linatge ho lo darrer dels falcons és aquell qui és molt poch en sa cantitat, e és apellat mirla, ${ }^{273} \mathrm{e}$ en romans la apellan hom guerli. ${ }^{274} \mathrm{Jat}-[135 \mathrm{v}]$ sia asò que aytal linatge sia menor en cantitat dels altros falcons damunts dits, emperò aytant ardit és con negun dels altros, segons sa cantitat he sagons lo poder ${ }^{275}$ que ha. E, mayorment, com hés ardit per doctrina he per hús he per esperansa de ayuda del falconer qui li és de prop; enaxí que en Gillem, falconer, deÿa que ab aytals ell avia ya presses grues. Los aucells qui no an gran poder són axí com a perdius ho coloma si, donchs, les lurs fortalesses no són ajudades per art.

Aquest linatge de falcons an senyals en la cara axí com los altres, e an molt longues les ales e sguardament de son cors, e ha la coha de bona mesura, e les cames he los peus plens de colós citrina, e és manor que esperver, e sa cantitat és axí com un aucell que hom apella mosquet. ${ }^{276} \mathrm{E}$, con és salvatge, pren ${ }^{277}$ uns aucells a qui diu hom carduells, ${ }^{278}$ per so con és molt bo voledor e qui sab bé agaytar. E, prenent, munta he devalla firent, axí com los altros linatges de falcons. Com aquell linatge quax és conegut per tots, e per so basta so que n'avem dit.

Tres linatges són de falcons no ${ }^{279}$ nobles, los quals nomenaren ${ }^{280}$ los antichs paradors, [136r] axí com Obtolomeu he los altres, so és saber: Guila, Gumet e Tesdorion. ${ }^{281}$ Aquests són apallats

271 poruchs] poctss poruchs ms.

272 XXXXIV] om. ms.

273 mirla, 'ocell de l'ordre dels falconiformes, de la família dels falcònids (Falco columbarius), el més petit dels falcons europeus', mirle AG.

274 guerli] smirlin AG.

275 poder peder ms.

276 mosquet, 'falcó de talla petita'. Hàpax. muscetum AG.

277 pren] pre ms.

278 carduell, 'cadernera', carduellos AG.

279 no nobles] nobles ms., ignobilium AG.

280 nomenaren] nomenarem $\mathrm{ms}$.

281 Guila, Gumet e Tesdorion] Aquila, Symacus et Theodothyon AG. 


\section{Marinela Garcia Sempere. El Llibre dels ocells de caça, o Flors de les receptes medicinals per a ocells de caça}

laners ${ }^{282}$ mills que falcons he alguns resemblants. Los germanans apellen aquest an lur langatge laners, ${ }^{283} \mathrm{e}$ alguns los an acostumats de apellar sionet, ${ }^{284} \mathrm{e}$ altres an dit burquers. ${ }^{285} \mathrm{E}$ saguexen les rates per los camps, e an diferència en color de blanquor he de nagror, e an cantitat de falcons; e lo roig, qui és menor, que semble mirla.

Con aquests són jóvens, en lo comensament, per la humor he per la tale rebonar ${ }^{286}$ quax no són de nagun ardiment. Axí con tots los infants són pahoruchs, mas, con són mudats dues ho tres veguades e la lur volpehitat natural ha pressa metzina per art, ladonchs pren coloms, a vagades lebres, conills, si bé és adoctrinat. Aquesta art deu hom tota hora tenir; que l primer any om los amansa he los domda hom, e que no ls don hom a menyar ${ }^{287}$ sinó aucells vius. E, com un poch los aurà plomats, lex-los hom hanar, enaxí que ls escapen de les mans, no primerament que volen, mas que córeguen. Con ells auran aprés de saguir aquests aucells, depuys lex-los om anar los aucells que auran picat de volant he corrent. E, con asò auran aprés per lonch hús, adonchs lex-los hom anar los aucels de volant ab les ales un poch trencades. E, a la per fi, lex-los hom anar ab totes lurs [136v] ales entregues de volant.

En totes aquestes cosses los deu hom apellar alta veu e escomoure, e lo falconer li deu ajudar a tenir l'aucell ${ }^{288}$ com per so ell ne reb ardiment. E, al segon any, ell prendrà ya de mayor aucells, cor tot aucell ${ }^{289}$ de aquesta manera rep ensemps nodriment he ardiment per les cosses damunt dites. E, aprés, pren haquels que 1 falconer vol. Jatsesia asò que ls aucells de la primera noblesa no agen ops so que damunt és dit, los quals són VIII dels primers linatges, enperhò molt val a créxer tot ardiment.

Aquestes cosses damunt dites basta prou ésser dites de la simpleha ${ }^{290}$ dels falcons.

Cor, dementre que cascuns de aquests linatges és ensemps mesclats ab altre, molts linatges de falcons ne són fets. Mas aquells que són pervenguts a nos són IIII, ${ }^{291}$ cor lo falcó pelegrí sovén se mescla ab aquells qui an los peus blaus. E, quant aquest mesclament se fa ensemps de pelegrí tersol

282 falcó llaner, 'falcó de l'espècie Tinnunculus cenchris, de color blanquinós amb taques fosques'.

283 laners] lavers ms., lanere AG.

284 sionet] sweimere $\mathrm{AG}$.

285 burquers] butherii $\mathrm{AG}$.

286 tale rebonar] hebes calidum AG. La lliçó del manuscrit ací està corrompuda.

287 menyar] menjas ms.

288 l'ancel] lancells ms.

289 aucell aucell pendra ms.

290 simpleha] dissiplina JQ, audaciam et periciam AG.

291 IIII] III ms.

SCRIPTA, Revista internacional de literatura i cultura medieval i moderna, núm. 17 / juny 2021 / pp. 280 - 336 ISSN: 2340-4841 · doi:10.7203/SCRIPTA.17.20915 
he de aquell prim qui à los peus blaus, lavors molt poch se lunyen de nobleha, com la sament del mascle és hobrant, faent he fermant per lo esperhit de virificació que aporta la virtut paternal en la fenbra ${ }^{292}$ qui li és supdita. E axí lo para ${ }^{293}$ are senbla lo pare, jatsesia asò que en los peus aya una poca de color de atzur. Mas, con de asò sia fet lo contrari, so és a saber, que $l$ para no sia bo e que la mara sia nobla, ladonchs lo pare ${ }^{294}$ resembla fortment lo pare, [137r] que no és bo he ha poca de la noblesa en si de la mara.

Enaxí con avem dit que de aquests dos falcons se fa mesclament ensemps, enaxí dels pelegrins que volen solitaris sovín per les terres és fet mesclament ensemps ab los laners negres, e a vegades ab los blanchs, ${ }^{295}$ e a vagades ab los rogs; e per la sament qui acosta, per la complecció semblen ensemps, e per l'espay del temps de l'enprenyament ${ }^{296}$ dels hous e de la companyiha, ${ }^{297}$ lo pare ${ }^{298}$ és creat he resembla a cascunes de les parts. E asò se fa entre los aucels e ls bestarts, segons que aquesta cossa és manifesta en los libres que són estat fets ans de aquest. Aquest mesclament se fa e los falcons de diverses espèssies qui s'acosten he són vaÿnes en conplecció, en lo temps que 's mesclen ensemps se atroben, e asò fan con no atroben linatge de la lur espèsia ab qui ss mesclen.

Jatsia asò que nos ayam dits IIII linatges de falcons en aquesta guisa mesclats ensemps ésser venguts a nos, emperò rahó requer en molt d'altros mesclaments tot dia ne poden ésser fets. E nos crehem que sia aquesta la raó com diversos linatges de falcons són trobats en diverses regihons. Jatsia asò que diverses regihons fassen les costumes e les colors de les bèsties ésser diverses, enperò la rahó de les diverses espècies fan diversitats, mayorment ${ }^{299}$ lo mesclament ${ }^{300}$ que nos avem dit, segons que nos avem vist $[137 \mathrm{v}]$ en los linatges de les hoques e dels cans e dels cavals en nostre temps.

E hasò no és fet ten solament en los linatges dels falcons ensemps mesclats, enans és fet del linatge dels falcons ab los estors e $\mathrm{ab}$ los espervers e $\mathrm{ab}$ los linatges ${ }^{301}$ de les hàguiles; és provat ${ }^{302}$ que són

292 paternal en la] paternall en la <gutta de la> fenbra JQ, paternae virtutis in subiectam feminae guttam AG.

293 para] partus AG, 'fill, cria'.

294 pare] partus AG, 'fill, cria'.

295 blancbs] blaus ms., albis AG.

296 emprenyament, 'acte i efecte d'emprenyar o fecundar'.

297 companyiba] companyiha, <llurs sements mesclades es pertorben i es transformen i es completen mútuament, i> JQ.

298 pare] partus AG.

299 mayorment $<\dot{s}>$ mayorment JQ.

300 mesclament tomensament mesclament $\mathrm{ms}$.

301 linatges] linatge ms.

302 provat prossat provat ms.

SCRIPTA, Revista internacional de literatura i cultura medieval i moderna, núm. 17 / juny 2021 / pp. 280 - 336 ISSN: 2340-4841 · doi:10.7203/SCRIPTA.17.20915 
fets diveros mesclaments ab generació de diversos aucells de cassa que són conposts. ${ }^{303}$ Mas, en $\operatorname{los}^{304}$ denant dits IIII linatges, mayorment avem dit que n feu mesclament e ajustament de falcó pelegrí, per so con los pelegrís, mantinent que són nats, són gitats per lurs pares delà on nexen, e sovín se pertexen los uns dels altros per presa ${ }^{305}$ he per hira. E, con no atroben de la lur espècia ab qui s puxen mesclar, ells se mesclen ab los pus semblans que puxen trobar d'altre espècia en lo temps con se deuen cavalcar. E, con se mesclen ensemps ab aquell qui ha los peus de color de azur, quax de aquell qui despuys nex és senblant a palagrí; e, con se mescle ab lo laner negre, hix-ne falcó negre, qui no és bo hi és senblant al negre; e, con se mescle ab lo blanch, ${ }^{306}$ hix-ne falcó blanc e és semblant al blanch; e, con se mescle ab lo laner roig, hix-ne falcó roig e és senblant al roig en figura e $n$ color.

Aquests falcons hitalihans, qui són en aquesta guisa mesclats he conposts pus leugerament són $[138 \mathrm{r}]$ ajudats $^{307}$ que aquells qui de tot en tot freturen de noblesa e, mayorment, si lo pare és noble, com molta de noblesa rep d'ell, axí com avem dit en los libres de aquesta siència. Mas, si és lo contrari, enaxí que la mare sia noble he que lo pare fretur de noblesa, aquell qui serà nat de aquells aytals aurà menys de noblesa he menys bonessa, mas, enperò, per bona doctrina reebrà millorrament e, mayorment, haprés de un any ho de dos en aquella manera que dessús avem dita.

Aquestes cosses que avem dites basten ara dels linatges dels falcons e de les natures com per asò dit poran ésser coneguts.

D'aquí avant direm de les metgies he dels ${ }^{308}$ regiment dels falcons.

\section{Capítol xxxvir. ${ }^{309}$ Que parla del regiment dels falcons, lo qual és pertit en tres regiments}

Lo regiment dels falcons és pertit en tres regiments, so és a saber, en regiment de domdar e en regiment de sanitat e en regiment de malaltia.

303 conposts] conpots ms., conpositarum AG.

304 los] $10 \mathrm{~ms}$.

305 presa] preha ms., praedam AG.

306 blanch] negre blanch ms. album AG.

307 ajudats] ajudants ms., ajudats <per art> JQ, facilius iuvantur AG.

308 dels] dels ms.

309 XXXVII] om. ms.

SCRIPTA, Revista internacional de literatura i cultura medieval i moderna, núm. 17 / juny 2021 / pp. 280 - 336 ISSN: 2340-4841 · doi:10.7203/SCRIPTA.17.20915 
Lo regiment de mansedar he domdar ha dos ${ }^{310}$ térmens, dels quals la un és [138v] que s'acostumen ${ }^{311}$ a la mà de l'hom, he altre és que sia fet ardit he abrivat en la pressa dels aucells. Lo primer regiment si és que nuyll temps no li don hom a menyar sinó sobre la mà, com per asò ell se acostuma ${ }^{312}$ de l'hom. E ama lo banifet que hom li fa, e enclina son cor, segons que diu Seneca. ${ }^{313}$ Primerament, quant hom los deu amensadar, meta-li hom lo capell davant la vista, e sia tengut en la mà entro a tèrsia. Lavós, don-li hom a menyar una cuxa de guallina e, con la aurà manyada, pos-lo hom sobre un cavallet baix al sol e possa davant aygua en què 's bany si 's vol e, despuys, lexe'l estar al sol entrò que 's sia bé denayat e mundat. Puys, sia mès en un loch escur entrò al vespre, e puys, prin[... $]^{314}$

\section{[139r] Capítol primer. Per falcó costibat de ventrel}

És conegut com à lo ventrel gros e dur e à la cara torbada e asaborex-se sovent la boca e no pot esmirlar luny, espesialment en dejú. Si l vols curar, fes la madecina següent: ${ }^{315}$

Prin un tros de sucre candi, aytant com una avellana grosa, e tin-lo en la boca un poc; e prin lo aucel e mit-li lo sucre en la boca en guisa que 1 se n'enviy. ${ }^{316} \mathrm{E}$, aprés del sucre, mit-li en la boca aygüe neta e clara, aytant com cabés en mige closque d'ou. E, com l'aucel aurà ben payit he ben esmirlat, pex-lo de una cuxe de pol e dona-li lo fel del pol ab un poch de fetge. E, lo dia aprés sagüent, prin un tros de budel de gualina, tant com mig dit de larc, e sia ben levat ab aygua, e sia liguat a la un cap ab fil prim; e umple aquel budel del milor oli de olives que puxes trobar. E, aprés, ligua lo budel en l'altre cap. E prin lo falcó he mit-li aquel budel per la boca; e, com lo falcó aurà bé gitat aquel oli fora e aurà bé esmirlat, prin $[139 \mathrm{v}]$ aygua tèbeya e pex-lo de cor de crestat o de moltó o de cabrit $\mathrm{o}$ de lebre, e banya aquel cor sovent en l'aygüe tèbea.

310 dos] III ms., duos AG.

311 acostumen] acosten ms., assuescat AG.

312 acostuma] acostuma $<$ a la mà $>\mathrm{JQ}$, manum consuescet $\mathrm{AG}$.

313 Seneca] Symacbus AG.

314 La darrera línia queda inacabada. La resta del foli queda en blanc. El foli següent comença per la meitat també, amb un altre tractat sobre medicines dels falcons, el que hi havia a l'índex del manuscrit. Això vol dir que el capítol anterior queda inacabat $i$ ara comença un altre tractat de caça.

315 Ací comença un altre tractat.

316 enviar-se, 'empassar-se, deglutir'.

SCRIPTA, Revista internacional de literatura i cultura medieval i moderna, núm. 17 / juny 2021 / pp. 280 - 336 


\section{Marinela Garcia Sempere. El Llibre dels ocells de caça, o Flors de les receptes medicinals per a ocells de caça}

\section{Capítol segon. Per a pentex de ocel}

Per aucel qui à pentex és conegut que, aprés que s’és debetut, él pentexe. Si l l vols curar, prin un cor de porch, e ages de la let de cabre, de la cabre vermella. E prin dels pèls del porc dels pus prims, e sien capolats pus menut que pusques. E mulla lo cor del porch en la let desús dita, e scanpa sobre lo dit cor dels pèls, e done-li’n una gorga. E gorde’t que no ports lo falcó prop foc ni en loc calt, ne 1 tengues molt al sol sinó poc. E guarde'l del vent, e pose'l al pus fret loc que troberàs, e guarde'l que no 's debata. E dóna-li de la menta sana dues veguades la setmana. E da-li a menjar pols ab los ossos, los altres dies de la setmana, sens ploma; e, si és d'estiu, dona-li aucellets patits de niu. E estigua denant l'aucel tot lo jorn un librel d'aygua neta en què s bany con se volrà. E asò fe fins que sia guarit.

\section{Capítol terç. A grans qui s fan en la boca dels alcels qui s’apelen guarniols}

Aucel qui a guarniols, si 1 vols guarir, prin sucre candi, tant com una avellana grosa, e mit-lo-li en la boca, e, aprés del sucre, prin aygua neta, tanta com cabés en mige closque d'ou, e done-li a menjar cor o cuxe de pol banyat en aygua freda e ensalguada ${ }^{317}$ de sucre blanc. E prin una ploma d'oca qui tal bé, e escure'n aquels garniols o grans de la boca e de la lengua e del peledar, en guissa que n'hisque sanch. E prin aprés un tros [140r] de drap de li prim qui sia nou, e prin un poc de vi blanch, e mit en lo vi un poc de alum ${ }^{318}$ de roca moylt, ${ }^{319}$ e banye'n aquel drap en lo vi, e fregue $n$ aquel loc on axirà la sanch, e aprés prin lo drap e torna freguar altre veguada com sia banyat d'axò matex. E asò sia fet tres veguades solament. E, com aquesta madesina serà feta, lo matí e lo vespre següent prin melrosat e prin un bastó prim, e al cap del bastó sie enbolcat un poc de cotó ligat ab fil. E banya aquel cotó en la mel, e de part de dins del carcanyel sie bé escurat ab aquel ${ }^{320}$ melrosat alà on sien les nafres. E la lengua unte'n del melrosat dos veguades lo jorn, e fet aquest escurament per tres dies. E, pessats aquests tres dies, si lo past que li darets és fret, sia banyat ab aygua calda e desús untat ab un poc d'oli. E aquest past li donarets per tres vaguades la setmana; e, si lo past és calt, sia untat ab un poc d'oli. E adoba-li lo bec que l'age un poc curt, e dona-li a tirar. Banyar-li as les nefes ab aygua tèbea.

317 ensalgar, 'cobrir de farina o d'altra matèria polsosa'.

318 alum, 'sulfat doble d'un metall trivalent i un altre monovalent capaços de cristal litzar en octaedres regulars amb dotze mol lècules d'aigua de cristal lització'.

319 moy/t llegiu molt

320 aquel aquelta $\mathrm{ms}$. 


\section{Marinela Garcia Sempere. El Llibre dels ocells de caça, o Flors de les receptes medicinals per a ocells de caça}

\section{Capítol quart. Aucel qui age lo cap inflat e lo peledar}

Per aucel qui age lo cap inflat e lo paladar, si l vols curar, ti'l larc de ventre, axí com en lo primer capítol és escrit. E adoba-li lo bec que 1 tingua curt. E prin una lenseta de barber e toca-li en la infledura desús dita del peledar, en la part defora, envés la part del bec, en guisa que n’hisqua sanch, e asò solament en un loc. E prin dos grans de pebre moylts e mescle'ls ab un poc de grase molta, e fen un poc de empastre ab una guota de mel, pasa-la-li en la nafre que as feta ab la lenceta. E, lo matí aprés, vinent en dejú, prin IIII grans de caparàs e pique'ls e esclafa'ls e mit-[140v]los en un drap dins un poc d'aygua tèbeya, e mit-ne una gota en cascuna nefe, ${ }^{321}$ e guarde't que no li'n metesses en l'uy ni en la boca. E possa l'aucel al sol e lexa obrar la madesina. E, quant te aperà que la medesina age obrat, prin aygua tèbeya e ages cotó e banye'l en l'aygua tèbea, e mit-ne per les nefes de l'aucel IIII o V veguades. E, aprés, sucle-li les nefes ab la boca una veguada o dues. E, aprés, prin un poc de vin blanc, e ab lo cotó mit-ne per les nefes una gota. E, aprés una pessa, mulla-li la cara ab aygua clara bé de aventatge; e, aprés, pose'l al sol tro que sia axut. E, puys, leve'l de aquí e torne’l a la perxe en loc fresc. E, al vespre, fe-li tirar una cuxa de pol e da-li a menjar los ossos trencats ab les dents; e, altre dia, da-li ha menjar una cuxa de pol banyada en aygua freda, e porta l'aucel en un loc per banyar; e, si no 's vol banyar, ruxa-li la cara e sots les ales, e aporto'l al sol tro que sia axut. E tots dies fe-li tirar una cuxa de polla, e tin-lo larc de ventre, axí com se contén en lo primer capítol, e da-li pasts de perdiu calda dues veguades la setmana. E, si fer-se pot, fe-li plomar una ala de alcel sovent.

\section{Capítol vè. Per cascadura de ocel}

Aucel que sia trancat o cascat dintre, e no puxe engrexar ne puxe menjar, e fa sanc com esmirla, prin, primerament, un colom paoner petit e aranque-li la una ala. E prin lo cor e lo fetge del colom; e ages un poc de momia picada, e fen lo cor del colom, e al mig mit momia picada, e da-li'n a menjar del colom matex mitge gorgua sens ossos e sens ploma; e da-li'n pus poques picades que pusques. E, aprés, ages mige unça de ermodeculi e mige unça de turbit ${ }^{322}$ e una unça de sucre candi e una unça de sucre blanc; e pique aquel bé cascun per si e, aprés, mescle-u ensemps. E estoge-u en un paper, [141r] e da-li’n a menjar una veguada lo jorn, e mit-hi de la pólvora. E asó fe un dia e altre no, e, com l'aucel o menjarà volentés, ${ }^{323}$ da-li'n a menjar molt en una veguada lo jorn ab past calt, cassant e no casant. E, si és san l'aucel, da-li'n ab past calt o fret dos veguades la setmana.

321 nefe] nefle ms.

322 turbit, 'planta convolvulàcia de les Índies, de l'espècie Operculina turpetbum, d'arrels tuberoses i purgants'.

323 volentés] volentesa $\mathrm{ms}$.

SCRIPTA, Revista internacional de literatura i cultura medieval i moderna, núm. 17 / juny 2021 / pp. 280 - 336 ISSN: 2340-4841 · doi:10.7203/SCRIPTA.17.20915 


\section{Marinela Garcia Sempere. El Llibre dels ocells de caça, o Flors de les receptes medicinals per a ocells de caça}

\section{Capítol viè. Si vols tanir san l'aucel tot l'any, fes so qui s seguex migant abril, ans que 1 metes en muda}

Prin de la gerepigua aytant com una fava, e prin levor d'erbe cuquera, e fregua-la bé en les mans, e mescle-u e paste-u, e fe'n un rodolí, axí com una avellana grosa. E prin oli apati ${ }^{324}$ aytant com un siuró, e mol-lo ab lo mànech del guavinet sobre un talador de fust, e enbolca lo redolí de ${ }^{325}$ aquesta pólvora en guisa que la pringua tota. E ages une canele ${ }^{326}$ de sera, e prin lo falcó destrement, e mit-li haquel redolí en la boca, e ab la candela enpeny-li lo redolí fins aquel age a mig carcanyel. ${ }^{327} \mathrm{E}$ prin de la gerepigua sola, e ab lo dit fregue-li'n bé lo peledar, e tin-lo en loc fresc, e fe-le-y tenir tant com poràs. E, si ho vol gitar massa tost, mit-li un poc de aygüe per les nefes. Com lo age tengut prou, pose'l al sol, e, com age bé gitat, leve'l del sol e porte'l a la aygua per benyar, e, si no ss vol banyar, ruxe-li la cara. E, al vespre, pex-lo de un colom paoner o de una cuxa de gualina, e da-li ploma. E, aprés, pasats VIII jorns, prin de la caguamuge de la manuda viII grans e munde'ls bé de les escorxes. E prin dos guavinets bé nets, e ages un poc de la pel del col de [141v] una polla. E ab la un dels guanivets sobre l'altre, esclafats cascun per si, e mit-los de un en un sobre la pel, e tors-lo ${ }^{328}$ bé com un botó, e forada-lo bé menut ab una agulla e mit-ho a la boca del falcó; e, al vespre, pex-lo de una cuxa de gualina no masa.

\section{Capítol viıè. Per baxar falcó}

A falcó qui exirà de muda, si 1 vols baxar, da-li a menyar pol petits gran gorgua, IIII o v veguades, e aprés da-li a menjar pols grosos, axí com una perdiu, neguats en aygua e frets. Da-li'n a menjar la maytat al matí e l'altre meytat al vespre, ab ploma e ab ossos. E, com sia baxat bé xx o xxv jorns, fe'l volar a cassa, e, com aya cassats VII o VIII jorns, no li dons ha menjar massa gran gorga de la cassa que cassaràs; e, lo dia que no cassaràs, da-li a menjar cran banyada en aygüe frede. E, aprés, adobe-li lo bec de la giripigua, axí com demunt és dit, e no li dons de la cassa pus si donchs no era de hivern o fes grans frets, axí com demunt és dit. E, puys, fes engüent de blanch d'ou e fel de bou, e debat-ho tant que torn engüent.

\section{Capítol viIIè. Per porets}

Si vols guarir aucel qui age porets, fe-li axir sanch de totes les ungles ab un guanivet. Aprés, ages vinagre e alum de roca e sal, e pique'l bé e mescle-u ab lo vinagre, e ab un poc de cotó banyen-li'n les mans deval e demunt. E fe estar lo falcó sobre un sach de sal, e banye’l bé [142r] de vinagre, e estigua lo falcó de nit e de dia sobre lo sac demunt dit de sal.

324 oli apati] àloe pati JQ.

325 de] be ms.

326 une canele] dues caneles ms.

327 carcanyell, 'gargamella'.

328 tors-lo] torcs-lo $\mathrm{ms}$. 


\section{Marinela Garcia Sempere. El Llibre dels ocells de caça, o Flors de les receptes medicinals per a ocells de caça}

\section{Capítol viIIè. A tota trencadura de dit o de mà o de cama de falcó}

Prin clare d'ou e pedre marbre, e mol-le bé, e prin forment masteguat, e mescle la pólvora ab la clara de l'ou, e posse-u sobre la trencadura, e possa desús lo forment mesteguat. E, aprés, prin un poc de pegunta molta e mit-ne sobre tot. E prin un poc de drap de li prim e ligua-lo ab fil prim sobre tot asò. E, aprés dos jorns, leve lo fil e estigua l'aucel xv jorns que no vol, e estigua en cassa fosca, que no 's debata, e axí serà guarit.

\section{Capítol xè. Per falcó qui no pugua gitar la gorgua ne la pugua pessar}

Prin aygüe tèbeya e un poc de cotó e banye'l ab l'aygüe tèbea en les nefes. E prin lo falcó e umple-li la gorgua de la dita aygüe entrò que sia molla. E, aprés, mit-li lo dit en la guorga, al cap dels pits, defore, e tira-le-y amunt e axir-n'à tota. E, gitada la gorgua, umple-la-li altre veguada de la aygua tèbea, e fe-le-li gitar altre veguada. E, aprés, prin dos clavels de girofle e un poc de sucre blanc, aytant com una avellana; e pica-ho tot ensemps e detrempa-o ab aygua calda e mit-lo-y dins la gorgua. Aprés estigua en loc calt, e no li dons a menjar entrò al vespre, e da-li un petit de colom.

\section{Capítol xiè. Per pessar bé los pasts a falcó e estor o esperver}

[142v] Si estor, falcó o esperver volràs tanir sa que pas bé les viandes, prin a veguades lexiu ben colat e banye-y la carn ${ }^{329}$ que li deràs a menjar, e pex-lo axí dos dies; altre dia da-li a menjar carn 330 de boc ab mentegua e pols de màstec. ${ }^{331}$ Pex-lo axí per tres dies.

\section{Capítol xıı̀. Per ocel malalt}

Aucel qui sia malalt, prin una coloma qui vol poc e gita-la-li denant en guissa que no pusque fugir; e tingua-la entre les mans, e aurà gran dalit ab ella, e da-li de la sanc a beura.

\section{Capítol xIIIè. Per ocel que om no sap quina malautia ha}

Si no saps quina malaltia ha l'aucel, pex-lo ab limedures de ferro, e possa de les limadures en la $\operatorname{carn}^{332}$ calenta, e gite-y mel e oli rosat mesclat ab les limedures del ferre.

329 carn] cran ms.

$330 \mathrm{carn}] \mathrm{cran} \mathrm{ms}$.

331 màstec, 'planta de la família de les compostes, de l'espècie Chondrilla juncea, que creix pels camps de conreu i és collida per a fer-la servir d'enciam'.

$332 \mathrm{carn}] \mathrm{cran} \mathrm{ms}$.

SCRIPTA, Revista internacional de literatura i cultura medieval i moderna, núm. 17 / juny 2021 / pp. 280 - 336 


\section{Marinela Garcia Sempere. El Llibre dels ocells de caça, o Flors de les receptes medicinals per a ocells de caça}

\section{Capítol xıIIIè. Pel alcel qui à fàstic e no pot menjar}

Si l'alcel à fastix e no pot menjar, prin un aucellet e unte'l ab mel e ab horíi ${ }^{333}$ demunt e ab pols de màstech, e da-li'n a menjar. E, si gita so que aurà menjat, prin una teula que sia bé levada e neta, e pica-la bé; e, com serà bé picada, sia la pólvora bé sernuda, ${ }^{334}$ e gite’n sobre la $\operatorname{carn}^{335}$ que li deràs a menjar tres dies. E, puys, da-li a menjar cuxa de gualina o cor de gualina banyat ab suc de donzel. ${ }^{336}$ Axí pex-lo per tres dies ab les limadures demunt dites. [143r]

\section{Capítol xvè Per aucel qui à pepida ${ }^{337}$}

Si aucel à pepida, és malautia qui dona tost la mort. Prin un aucellet e fen-lo, e ab lo ventrel e ab lo fel fregue-li la lengua. E, puys, da-li a menjar fetge d'anguila.

\section{Capítol xviè. Conexense de l'alcel com à febre}

Aucel qui age los peus morats e mudats, e ha los uls carnossos e torbats, levors à febre. Prin leu 338 de colom e creme'l e fe'n pólvora, e posse'n sobre la cran ${ }^{339}$ que li deràs a menjar. E, si d'aquesta pólvora no pot menjar, prin fel d'enguila e fe-li que 1 meng entregua. Prin riubarbre e mit-lo en aygua e da-li’n a beura. E prin les entramenes de un colom e seque-les bé e fe-li’n pólvora e da-li'n a menjar ab la carn.

\section{Capítol xvirè. A dolor de cap de ocel qui comens als uls}

Aucel qui à dolor al cap e comense als uls, prin lo suc de la rel del fanol e oli de liri, vermels d'ous e let de dona qui nodresque infant mascle, e mescle-u tot ensemps, e unte-li'n los uls tant fins que guoresque.

333 hor] bon viJQ.

334 cernut, 'tamisat'.

$335 \mathrm{carn}] \mathrm{cran}$ ms.

336 donzell, 'planta de la família de les compostes, de l'espècie Artemisia absynthium'.

337 pepida, 'tel escatós que es forma sota la llengua de certes aus, sobretot de les gallines, per acumulació de mucositats, i que constitueix una malaltia contagiosa’.

338 lleu, 'pulmons'.

$339 \mathrm{cran}]$ llegiu carn

SCRIPTA, Revista internacional de literatura i cultura medieval i moderna, núm. 17 / juny 2021 / pp. 280 - 336 


\section{Marinela Garcia Sempere. El Llibre dels ocells de caça, o Flors de les receptes medicinals per a ocells de caça}

\section{Capítol xviIIè. A lumbrifeli, so és, aucel qui no pot volar axí com à acostumat}

Aucel qui no pot volar axí com sol e à les ales sanes à malautia que apella om lumbrifeli. À aquesta cura: prin una enguila e cou-la bé en aygüe; e cul lo grex que n'axirà, e pose’l so ${ }^{340}[143 \mathrm{v}]$ sobre la cran que mengerà. E unte-li'n la lengua he les nerils ab lo dit grex, e guorrà. E prin l'aygüe on serà cuyta la enguila e banye'n l'aucel, e puys pose'l al sol una estona. E asò fes per tres dies.

\section{Capítol xvıIIİ̀. Conexensa com l'aucel $\mathbf{a ̀}^{341}$ mal en la vaxigua}

Aucel qui ss debat per beura aygüe à dolor en la vaxigua. Prin alum de roca ${ }^{342}$ e da-li'n a menjar ab la cran un past. E, la segona vaguada, da-li a menjar cran de boc ab mel e ab mantegua per VIII $^{343}$ dies, e posa-li damunt sanc de colom, e pose l'aucel a l'aygua e begue'n aytanta com ne volrà.

\section{Capítol xxè. A mal de uls}

Aucel qui age los uls inflats, prin rel de ravagualest, ${ }^{344}$ pes de drachme e mig, e tres clavels de girofle e tres grans de caparàs; gingebre, dragme e mige, e xxx grans de mostalla; e tot asò pica ensemps. E prin grex de turtuga que no age aguts hous e bull-o tot ensemps en lo grex, e ab un drap poso'l en una capsa; e da-li’n a menjar lo primer dia IIII picades, lo segon dia dos picades, e axí cascun dia tro que sia guorit.

\section{Capítol xxiè. Aucel qui git sanc}

Prin sanc de dregó bé picada e mesclada ab bon vin, e dóna-li’n a menjar tres dies ab la cran que sia calenta. Enperò, a veguades los esdevé per molta sanc que beuen de la cassa que prenen e no an mester aquesta cura. Si li ve per trencadura o quesquedura, faràs-li la cura demunt dita. [144r]

\section{Capítol xxıè. Aucel qui age péra}

Prin àloes sicotrí, ${ }^{345}$ pes de tres dinés, e màstech, pes de VII diners, e coladana, pes de VII dinés. De tot asò fe pólvora e da-li’n a menjar ab la cran.

340 Aquest mot so pot ser el demostratiu neutre o la primera síl laba de la preposició sobre que trobem en la pàgina següent.

341 à] a sobre ms.

342 alum de roca] àloes JQ.

343 VIII] VII JQ.

344 ravagualest rava, gualesc JQ.

345 sicotrí, 'aplicat al sèver e àloe d'una varietat especial'. 


\section{Marinela Garcia Sempere. El Llibre dels ocells de caça, o Flors de les receptes medicinals per a ocells de caça}

\section{Capítol xxIIIè. Altre madesina milor a aucel qui age pedre}

Prin àloe pàtic e caparàs e pebre cumú, aytant àloe com del pebre, e la tersa part sia caparàs. E, de tot asò, fe pólvora, e da-li'n a menjar ab la cran banyada ab oli de ginyoli. E, si d'aquest oli no pots aver per benyar la cran que li daràs a menjar, prin rejola ${ }^{346}$ e fes-ne troses menuts, e mit-los en una lossa de fero e mit-hi oli e pose'l sobre lo foc, e bulla tant entrò que la reyola se age begut l'oli e que torn negre la reyola. E, puys, fe'n pólvora e da-li’n a menjar ab la cran ab les dites cosses ensemps.

\section{Capítol xxIIIIè. Aucel qui age poys}

Aucel qui age poyls, unte'l ab suc de malrubín ${ }^{347}$ e puys enbolque'l l'aucel en un drap blanc de li e stigua una pessa al sol. E prin femne de persona, e creme-la e fe'n pólvora e, de la cendre que n'exirà, gite-li'n demunt; e guarde que no li'n caygue en los uls ne en les orelles. Prin pebre comú o orpiment, ${ }^{348}$ e gite-li'n entre les plomes e en les rels dels canyons de les plomes de tot lo cos. E, si asò no pots aver, prin buyne ${ }^{349}$ de bou qui sia bé seca e fe'n axí com demunt és dit. Asò fet, pose'l al sol una estona.

\section{Capítol xxvè. Per aucel qui age poys, altre manera}

[144v] Prin malrubí, malvín e donzel, tot mesclat ensemps, cou-ho en aygua tant tro que torn a la tersa part, e ab aquesta aygua banya l'aucel ferm e pose'l al sol tro que sia axut.

\section{Capítol xxviè. Aucel qui à cuchs e hamagresque, los quals apelen filandres}

Si alcel à cucs e amagresque, banye-li la cran que li deràs a menjar ab aquesta aygua demunt dita; e tantost conexeràs que le maytat de la cran reté e l'altre meytat gita, que no pot retenir, e tantost la li deus tolre. E plome'l enfre les cuxes, e prin un budel de gualina e unple'l d'oli e bul-o un poc, e dona-ly a menjar destrement. E, si no 1 volia menjar, prin l'aucel destrement e mit-li aquel budel en

\footnotetext{
346 rajola, 'oli de rajoles significava oli fet d'una barreja d'oli d'olives amb pols de rajoles de terrissa'.

347 malrubi, 'planta labiada de l'espècie Marrubium vulgare, de moltes tiges, fulles ovato-orbiculars, cordiformes o cuneïformes a la base, flors blanques en glomèruls multíflors, amb bractèoles alesnades'.

348 orpiment, 'trisulfur d'arsènic, de color groc de llimona, molt tòxic, usat en tintoreria, pintura i pirotècnica, i antigament en medicina'.

349 buina, 'excrement de bou (en general)'.

350 malví, 'planta malvàcia de l'espècie Althaea oficinalis, tomentosa, de fulles molt espesses, apelfades, i flors de color rosa clar, l'arrel de la qual s'usa com a pectoral i com a emol lient'.
} 


\section{Marinela Garcia Sempere. El Llibre dels ocells de caça, o Flors de les receptes medicinals per a ocells de caça}

la boca e, ab lo dit, destrement enpeny-li lo budel fins que l'aya ben dins lo carcanyel. E, al ters ${ }^{351}$ dia, da-li a menjar cran banyada ab suc de donzel o ab suc de lengua bovina, ${ }^{352}$ aquella que 's $\mathrm{fa}$ per los prats. Si l'aucel no volrà menjar lo budel plen d'oli, banya la carn ${ }^{353}$ ab suc de ravagualest, e dona-li seres de bístia ben picades ab la cran, e auciurà los cuchs.

\section{Capítol xxviı̀̀. A conexense de aucel qui à mal d'escuma}

Aucel qui à mal d'escuma, conexerets entre les cuxes que à a manera d'escuma. Prin VII grans de pebre e tres cabesses d'ayls e IIII culerades de mel, e mescle-ho tot ensemps, e bull-ho ${ }^{354}$ tant tro que sie ${ }^{355}$ espès, e mit-lo en una capseta, e da-li a menjar cran de oqua o de bou ab la madesina. $\mathrm{E}$ da-li'n cascun dia tres vaguades tro que sia guarit.

\section{Capítol xxviıè. A tota malaltia que ocel age als uls, especial en la lila blanqua}

[145r] Prin èsula, ${ }^{356}$ que an los especiés, ben picat e sernut, e suc de ${ }^{357}$ rel de fenol e aygua rosada e let de fembre qui nodresca infant mascle, tant de l'un com de l'altro, e mit-ne tot dia en l'ul. E prin atzur e sucre candi, e pique'l bé, e pase'l per un sedàs, e gite-li'n en l'ull.

\section{Capítol xxvinIè. Per poret de ocel}

Aucel qui age porrets, prin latrera major, so és, marina. ${ }^{358}$ Trau-ne la let, e prin un drap de li blanc e banye'l en la let, e posa lo drap en la perxa on està l'aucel, e tengua les mans en lo drap, e estigue-y tota la nit, e al matí troberàs lo poret esclafat. E, tentost, leva lo drap de la perxe, e possa-hi un altro drap banyat $\mathrm{ab}$ vinagre, e prin grex de porc e unte-li'n la mà d'on lo poret serà axit.

351 ters] tercs ms.

352 lengua bovina, 'Planta de les espècies Anchusa azurea i $A$. undulata, de fulles ovals-allançades, flors en raïm amb la corol la blava o purpurina'.

$353 \mathrm{carn}] \mathrm{cran} \mathrm{ms}$.

354 bull-ho] bulle-ho ms.

355 sie] sies ms.

356 èsula, 'nom científic d'un gènere de plantes euforbiàcies'.

357 de de $\mathrm{ms}$.

358 marina, 'planta de diferents espècies del gènere Euphorbia, que, en trencar-se, dona un suc lletós'. 


\section{Marinela Garcia Sempere. El Llibre dels ocells de caça, o Flors de les receptes medicinals per a ocells de caça}

\section{Capítol xxxè. A pentax de ocel}

Prin femna de persona que sia bé sequa, e pica-la e banya-li la cran, e sia-hi mesclat suc de col.

\section{Capítol xxxiè. Aucel qui tengua sanch en la gorgua}

Prin Xxx grans de mostalla ${ }^{359}$ e v grans de pebre e un de caparàs, e piqua-ho ensemps tot; e prin un poc de sagí de porcella e mit-o en una lossa de ferro e trau-ne lo grex, e mit-hi les pélvores e posaho tot ensemps; e da-li'n ha menjar, e guarà.

\section{Capítol xxxıı̀̀. A sobròs ${ }^{360}$ de ocel}

A sobròs qui ‘s fa en la cama de l'ocel, prin vermels d'ous e unte'l-ne, e guarrà. [145v]

\section{Capítol xxxıIIè. A fer mudar tost ${ }^{361}$ ocel}

Si vols que l'aucel mut tost e age ${ }^{362}$ bones plomes, prin tortugues, pica-les e mit-les en un sac de li patit, e hisque'n tanta aygua con axir-ne porà, e banye'n la cran que mengerà l'alcel.

\section{Capítol xxxinè. Aucel qui no pusque ben pessar la vianda}

Prin tres grans de pebre, e torre'ls e pique'ls, e da-li'n a menjar ab la cran.

\section{Capítol xxxvè. Aucel qui git la cran}

Posa-li denant aygüe e begue'n aytant com ne volrà; e no li dons aquel dia res a menjar. E prin colada de let de cabre e trau-na lo sirigot; ${ }^{363}$ e prin un colom novel e trenca-li los pits; e, asò que n'exirà, mescle-ho tot ab la colada; e da-li’n a menjar. E asò fe dos vaguades.

359 mostalla, 'mostassa'.

360 sobròs, 'tumor dur que es congria sobre un os'.

361 tost tot $\mathrm{ms}$.

362 age] ages $\mathrm{ms}$.

363 sirigot, 'la part aquosa de la llet, separada de la coagulable'. 


\section{Marinela Garcia Sempere. El Llibre dels ocells de caça, o Flors de les receptes medicinals per a ocells de caça}

\section{Capítol xxxvè. Aucel qui té plomada vella en la guorgua}

Aucel qui té plomada vella en la guorgua, da-li tres plomades d'estopa mesclades ab mel, he da-li'n per forsa.

\section{Capítol xxxviıè. Aucel qui té cran al matí e no la pot pessar}

Aucel qui té cran al matí e no la pot pessar, da-li a menjar una cuxa de granota, e peserà-la.

\section{Capítol xxxviIÌ̀. Per porets de ocel}

Aucel qui à porrets, prin un drap de tapit ${ }^{364}$ bé pelós o un drap de feltre, e cus-lo en la perxe on à acostumat de estar lo aucel. E gite sobre [146r] aquel drap sal que sia ben picada, e gita-n’i molta; e prin orí d'ome e banye'n lo aucel e lo drap. E pose-y l'aucel, e guarà.

\section{Capítol xxxviIIIè. Per aucel qui no puxe engrexar}

Per aucel qui no puxe engrexar: fe-u possar que no $l$ ports, e da-li a menjar cran de porc més que d'altre cran; e da-li aucellets e gualines, e possa-li aygua denant, que 's bany tota hora que 's vulla.

\section{Capítol xxxxè. Aucel qui ha dolor en valessa}

Per aucel qui ha dolor en valessa, prin castafragia ${ }^{365}$ e girofle, de cascun tres grans, e picats-ho, e dats-li'n a menjar ab cran calenta tres vaguades.

\section{Así comensen les medesines dels estors.}

\section{Capítol xxxxiè. Astor o falcó o altre aucel qui aurà sanc $c^{366}$}

Per astor o falcó o altre aucel qui aurà sanch, da-li sanc de dreguó e monmia, e sia tot picat, e da-li’n a menjar tres dies.

364 tapit, 'catifa'.

365 castafragia] estafragia JQ.

366 sand sanc < al'esmirladura> JQ. 


\section{Marinela Garcia Sempere. El Llibre dels ocells de caça, o Flors de les receptes medicinals per a ocells de caça}

\section{Capítol xxxxıè. Aucel qui no vulla menjar}

Per falcó o estor o altre aucel qui no vulla menjar, muda-li sovent les viandes, e mengerà.

\section{Capítol xxxxıIè. Astor qui és melalt}

Prin un gra de nou e guoma de ginebre, e liga-o tot ensemps en un drap de li, e mit-hi desots cualiu, e estigua al foc tant tro que sia cremat. E fe'n pólvora, e mescle-y mel amb mantegua, e da-li'n a menjar ab la cran. [146v]

\section{Capítol xxxxıIIİ̀. Conexense com l'estor à mal en la vaxigua}

Conaxensa com l'estor à mal en la vaxigua: se conex, so és, cant l'astor beu l'aygua e ss debat, à dolor en la vaxigua. Lo primer dia, da-li a menjar cran qui age ales, ${ }^{367}$ l'autre dia, da-li a menjar cran de cabre mesclada ab mel, ${ }^{368}$ e banya-la ab sanc de colom, e axí pex-lo per tres ${ }^{369}$ dies.

\section{Capítol xxxxvè. Conexense com l'estor à febre}

Quant l'astor à febre, conexeràs que à les mans morades e tremudades de color, e los uls fort torbats, quax a blau de atzur. Prin les entramenes de un colom, e seque-les bé e pique-les, e da-li'n a menjar ab la cran calenta; e prin fel de gualina e da-le-y antregue a menjar. E, si no 'n pots aver, da-li riubarbre picat ab aygua.

\section{Capítol xxxxviè. Astor qui no pot mudar}

Prin una coloma $\mathrm{a}^{370}$ negre e mate-la, e fe-la coura ab forment; e dona lo forment a menjar a una gualina per $\mathrm{xx}^{371}$ dies. E, puys, dona a menjar la gualina a l'astor.

\section{Capítol xxxxviè. Astor a qui quaen les plomes per tinya, lo qual se apella formigua}

Prin ensens e màstec, tant de la un con de l'altre, e pica-ho tot ensemps, e mit-ho en lexiu, e estigue-y tres dies los dits màstec e ensens; e mit-ne a l'astor sots les ales, als coltels e als vans, e guarà.

\footnotetext{
367 ales] alos JQ.

$368 a b$ mel $a b<$ mantega $i a m b>$ mel JQ.

369 tres] ИII JQ.

370 coloma] colobra JQ.

$371 x X] I X J Q$.
}

SCRIPTA, Revista internacional de literatura i cultura medieval i moderna, núm. 17 / juny 2021 / pp. 280 - 336 


\section{Marinela Garcia Sempere. El Llibre dels ocells de caça, o Flors de les receptes medicinals per a ocells de caça}

\section{Capítol xxxxviriè. Astor qui à totes les plomes e no pot volar axí com sol}

[147r] Quant l'astor qui à totes les plomes e no pot volar, prin una lebre $\mathrm{e}^{372}$ e cou-la bé, e prin lo grex qui n'exirà, e da-li'n a ${ }^{373}$ menjar ab la cran.

\section{Capítol xxxxvinİ̀. Aucel qui à dolor en lo cap}

Quant l'astor o qualsevol aucel qui à dolor en lo quap, prin pebre e clavels de girofle, tot per agual pes; e pique-u bé e mescle-u ab mel, e posa-li'n sobre la lengua.

\section{Capítol Lè. Porgua a tot aucel}

Quant l'astor o qualsevol aucel volràs porgar, prin caguamuge, v grans, e pare'ls de la escorxe, e done'ls a l'aucel ab cran calenta, e sien los dits grans un poc picats.

\section{Capítol Liè. Aucel qui sia acolerat}

Quant l'astor o qualsevol aucel qui sia acolerat, ${ }^{374}$ prin aygua-ros e gite-li'n per les nefes; e prin un poc de mel, e mescle-la ab l'aygua, e estufa-li' $n^{375}$ en la cara, $\mathrm{o}$ ab bon vin blanc; e perdrà la calor.

\section{Capítol LIIè. Aucel qui à guarniols en la boca}

Quant l'astor o qualsevol aucel qui à guarniols en la boca, prin una agula d'argent e punx-los gualart ab la punta de la agulla, de guisa que li n'hisque sanc de cade un dels guarniols o grans que tindrà en la boca. E, aprés, prin un poc de vidre e pique'l bé; e, aprés, sern-lo ab un sedàs, de guissa que sia axí com a farina, E e, despuys, posa-li'n ab los dits gualart de la pólvora en cada un dels guarniols o grans, e asò fes per tres o IIII dies entrò que tu conexeràs que sia guorit. Emperò, $[147 \mathrm{v}]$ com tu li metràs la pólvora, mit-li un bastonet en la boca, de guisa que la boca tingua bedade una bona estona per tal que la pólvora pusque hobrar. E lo bastó sia aytal que no sia agut que, si era agut, consumar-li à la boca.

372 lebre] <cu>lebre JQ.

373 a] a betre ms.

374 acolerat acalorat $\mathrm{JQ}$.

375 estufar, 'esquitxar, llançar un líquid a gotes amb força'. 


\section{Asi $^{376}$ comense les medesines dels esperver}

\section{Capítol LIIIè. Esperver enreumesat}

Quant l'esperver és enreumesat o encadernat, bo és que om li do cran sadolament; e que sia fresque dels ${ }^{377}$ ranyons, enaxí que, en dos o en tres trosos, pos om sengles grans de pebre.

\section{Capítol LIIIİ̀. Altre manera per esperver enreumesat}

Quant l'esperver és enreumesat o encadernat, prin tecartich ${ }^{378}$ blanch e mit-li'n per la naril o nefa, e lexar-l'as astar per tot un dia en loc escur.

\section{Capítol Lvè. Altre manera per esperver enreumesat}

Quant l'esperver és enreumesat o encadernat, prin suc de ruda e mit-li'n en les narils o nefes, e per tot aquel dia no li dons res a menjar.

\section{Capítol Lviè. Aucel qui à gelosia}

Prin ruda $\mathrm{e}^{379}$ torra-la bé, e, puys, pica-la bé e cou-la bé en aygua. E, com le auràs cuyta, prin un drap de li e mit-hi la ruda, e pi-[148r]ca-la altre veguada; e, com serà picada, tors-la sobre la aygua on serà cuyta la dita ruda, e banyats-hi l'aucel, e guardats-vos no li'n caygua en los uls.

\section{Capítol Lviè̀. La conexensa dels falcons}

La noblesa dels falcons és coneguda per lo cap redon e, sobiranament del cors plana. Ítem, que age lo bec gros e redó, lo quol lonc e les espatles amples, les penes delguades e soptils. Ítem, que les cuxes sien longues, les cames curtes e groses, e que aya com és jova les mans blaves e bé escatoses e grans.

E deus-te ben gordar que no tengues nagun aucel a fum de pegua, ne a pudor de privada, ne en loc on amaren li ne càyem, ne en saler on aya vin novel.

376 Asi Gapt LIHè. Asi ms.

377 dels de $<$ ca o de molté, de $>\mathrm{JQ}$.

378 tecartich] o potser tetartich.

379 e] e $\mathrm{ms}$. 


\section{Capítol Lviriè. A fer mudar aucel}

Prin CCC caragols, e mit-los en un sac de li o de cànem, e sien trencades les closques dels dits caragols; e, puys, penja lo dit sac al sol, e aquella aygüe que 'n recorrerà meta-la om en una enpolla, e, com deràs a menjar a l'aucel, ab aquella aygua mulla-li lo past que li daràs. Axí mateix, si vols que isque de muda bel he net, prin vI o vII prunes verdes e creme-les, he, puys, mit-les en la aygua demunt dita, ab lo past da-li’n, perhò, com comensarà de lansar les penes, no metes en la cran de la dita aygua.

\section{Capítol LVIIIÌ̀. Per tanir aucel sa}

Si falcó o estor o esperver volràs tanir sans [148v] e que pas les viandes, prin a veguades lexiu bé colat, banye'n la cran que li daràs a menjar, e pex-lo axí per dos dies, e, l’autro dia, da-li a menjar cran de boc ${ }^{380}$ amb mantegua e ab pólvora de màstec. E pex-lo axí per tres dies.

\section{Capítol Lxè. Per desinflar mà de falcó o de estor o de esperver e estrènyer}

Prin mige unça de àloe e dues dinades de sera nova, e ab blanc d'ou ensemps lo àloe e lo blanc d'ou e un poc d'ensens; e lo ensens fa a molra en una pedra plana. E, tot asò molt, bul hom la sera, e mit-hi om les dites cosses moltes, e fa'n hom enpastre, e pose'n en la mà de l'aucel subtilment cossit, e guorà.

\section{Capítol Lxiè. Asperver qui à porets}

Prin un troset de val o de dosos e pele-u bé, he, com l'ages pelat, fer-n'as en la mà que aurà lo poret, un guant gentilment; e pendràs del diacaloy ${ }^{381}$ un poc, e fer-n'has un enpastrelet en lo dit guant, tant com tindrà la mà dejús. E, puys, subtilment cossir-lo-li as sobre la mà, dejús los dits, ${ }^{382}$ e lexar-lo-li as fins sia guorit. E, si és poret, él lo li esclatarà e 1 senerà, e, si no hera poret e fos infledura, qui per alguns cassos ve, la li desinflerà e le y estrenyerà. E, com l'aucel serà guorit, él matex s'o dirà, so és, que él ne estrenyerà la mà e farà la forsa matexa acostumada; e, lavorens, leva-li'n lo guant.

\footnotetext{
380 boc] poc ms. Seguim la correcció de JQ.

381 diacoloy] diacolon JQ.

382 dits] lits $\mathrm{ms}$.
} 


\section{Así comensan les madesines dels cans de cassa ${ }^{383}$}

\section{[150r] Capítol LXII. Qui parla per a gorir $\operatorname{los}^{384}$ cans de cassa ho de qualsevulla ${ }^{385}$ natura de ronya que agen}

Primerament, tu levaràs los cans ho qua ab lexiu ben fort, $\mathrm{e}$, tantost, de continent tu ls unteràs ab lo dit engüent, lo qual és per a hobs de dos cans perquè, segons que seran si u moltiplicaràs ho minveràs; ço és, que tu pendràs vi dinés d'argentviu e mige liura de sofre e mige liure de sagí e una liura de such de la laterra, ${ }^{386}$ dels brots, los quals picaràs, e ab un drap colar-ho has fins n'ages la dita canditat. E, axí matex, picaràs cada cossa per si, mes pendràs ab un gresal tanta canditat con poràs de aquella let que n'hexirà de la dita letrera. E, quant tot asò auràs fet e serà ben picat, sia mesclat e fet engüent. E, lavors, pendràs los cans ho ca e sien $[. . .]^{387}$ fregats a repel, e lexe'ls estar. E quant vendrà VIIII o x jorns que agen estat axí untats, tu, lavors, los pendràs e feràs-los ensebonar e fer-los as ben nets ho net. ${ }^{388}$

383 El foli140 és en blanc.

384 los] lo ms.

385 qualsevulla] qalsevulla ms.

386 laterra] latrera JQ.

387 [...] [untats e ben] JQ.

388 El foli 150v és en blanc.

SCRIPTA, Revista internacional de literatura i cultura medieval i moderna, núm. 17 / juny 2021 / pp. 280 - 336 ISSN: 2340-4841 · doi:10.7203/SCRIPTA.17.20915 